\title{
Philosophy of Mind and Cognitive Science since 1980
}

\author{
Elizabeth Schier and John Sutton \\ Macquarie University \\ lizschier@gmail.com \\ john.sutton@mq.edu.au
}

July 2011

For A History of Australasian Philosophy, edited by Graham Oppy and Nick Trakakis

\section{Introduction}

If Australasian philosophers constitute the kind of group to which a collective identity or broadly shared self-image can plausibly be ascribed, the celebrated history of Australian materialism rightly lies close to its heart. Jack Smart's chapter in this volume, along with an outstanding series of briefer essays in A Companion to Philosophy in Australia and New Zealand (Forrest 2010; Gold 2010; Koksvik 2010; Lycan 2010; Matthews 2010; Nagasawa 2010; Opie 2010; Stoljar 2010a), effectively describe the naturalistic realism of Australian philosophy of mind. In occasional semi-serious psychogeographic speculation, this long-standing and strongly-felt intellectual attitude has been traced back to the influences of our light, land, or lifestyle (Devitt 1996, x; compare comments by Chalmers and O'Brien in Mitchell, 2006). Australasian work in philosophy of mind and cognition has become more diverse in the last 40 years, but is almost all still marked, in one way or another, by the history of these debates on materialism.

In this chapter, taking up where Smart's narrative ends, we aim at a broad survey of more recent Australasian philosophy of mind and cognition, focussing on work done since 1980. In some of the fields we address, the boundaries between philosophy and related disciplines blur, with scientists participating actively in philosophical debates, and philosophers in turn working in independent research groups in automated reasoning, Artificial Intelligence, cognitive science, or cognitive neuropsychiatry. However we make no attempt at integrating intellectual history with institutional history, as has been done effectively in parallel international scholarship on these areas by Bechtel, Graham, and Abrahamsen (1998), and in Margaret Boden's extraordinary two-volume history Mind as Machine (2006): the tracking of earlier interdisciplinary interactions between philosophy and cognitive science in Australia could proceed backwards from the collections of essays edited by Slezak and Albury (1988) and Albury and Slezak (1989: see also Slezak 2010). Nor do we cover the wider cultural impact of mind-body debates in Australia, as does James Franklin in his chapter 'Mind, Matter and Medicine Gone Mad' (2003, 179-211). A full history of Australasian philosophy of mind and cognitive science would integrate participants' internalist perspectives on conceptual development with the more ethnographic approaches of social and cognitive studies of philosophy or science. It would require attention to local contexts and variations, to newly developing patterns of internationalization and collaboration, to the roles of cognitive theory in managerial and economic rationalist rhetoric and practice, and to changing patterns of funding and research policy at the levels both of local university strategy and of 'national research priorities'.

Within our narrower ambit, then, we try to take in philosophical work on mind and cognition done by anyone in Australasia or by Australasian philosophers working elsewhere. We apologize for inadvertent omissions and for residual Sydney-centrism (and Australia-centrism) in our field of vision. While making no pretence at exhaustive coverage even within the restricted domains on which we focus, we seek to cite a large enough array of primary sources by Australasian philosophers to give readers significant initial guidance in each area. Just because Australasian philosophy of mind and cognition has been so deeply embedded in international debates, this policy 
issues in a strangely partial picture. Readers of this chapter could thus usefully supplement it both with a larger-scale history like Boden's, and with some of the excellent textbooks and encyclopedias in the field. Six texts which together provide excellent coverage are Sterelny's The Representational Theory of Mind: an introduction (1991), Copeland's Artificial Intelligence: a philosophical introduction (1993), Armstrong's The Mind-Body Problem: an opinionated introduction (1999), Maund's Perception (2003), Ravenscroft's Philosophy of Mind: a beginner's guide (2005), and BraddonMitchell and Jackson's Philosophy of Mind and Cognition: an introduction ( $2^{\text {nd }}$ edition, 2006). Robert Wilson, an Australian philosopher working in Canada, coedited the authoritative reference work MITECS, the MIT Encyclopedia of the Cognitive Sciences (Wilson and Keil 1999), while another important guide is The Oxford Companion to Consciousness (Bayne, Cleeremans, and Wilken 2009).

The concepts of 'mind' and 'cognition' have mostly been assumed, by both philosophers and scientists, to be clear enough at least to get a research program going. Doubts about the integrity and utility of these terms have, however, been articulated. Some have emerged from within the mainstream, as in some forms of eliminative materialism, or in Tim van Gelder's (1998a) case that 'the traditional mind-body debate is chronically unwell'. Van Gelder first identified four metaphysical assumptions behind standard ways of setting up the mind-body problem: 1) the solution to the problem must make use of only the relations of identity, reduction, realisation, supervenience, and causation; 2) the mind is relationally homogenous with respect to the brain; 3 ) all mental entities belong to the one ontological category; and 4) that folk psychology provides the right level of analysis for individuating mental objects. By rejecting all four assumptions, van Gelder argued, we open the door for a pluralist conception of the ontology of the mind which has the freedom to appeal to a plurality of ontological kinds and relations when considering the relation of mind to the physical. Other doubts about the mind-body debate arise in non-Anglophone philosophical traditions (Albahari 2002, 2006; Chadha 2011). As Max Deutscher puts it, for example, 'within postphenomenological contemporary philosophy there is, deliberately, no single word for what is still called "mind" within the analytical tradition' $(2010,423)$ : he points to alternative locutions, by which 'one speaks of the capacities, skills and activities - both socially expressed and personally contained - of the perceptive, thoughtful and sensitive human being'. More radical rejections of established universalizing discourses of body and mind were generated in certain strands of psychoanalytic and feminist philosophy (Lloyd 1984; Grosz 1989; Diprose and Ferrell 1991; Ferrell 1992; Gatens 1996; Wilson 1998; Sharpe and Faulkner 2008). Significant historical and cultural contingency in our psychological categories (and in the very idea of a 'psychological category') has also been suggested in anthropology (Samuel 1990), cross-cultural semantics (Wierzbicka 1992; Amberber 2007; Schalley and Khlentzos 2007), and in the history of philosophy and history of ideas (Macdonald 2003).

The term 'cognition', in turn, is sometimes taken to encourage a rationalist focus on abstract thinking and reflection, to the exclusion of affect and embodied feeling. This is a reflection of the narrower visions of cognitive science which dominated the field until at least the 1980s, by which cognition is simply information processing and the mind just a system which receives, stores, and then transmits information, in a putatively unifying framework which many cognitivists hoped would one day also explain emotion, creativity, memory, and subjectivity. But broader, pluralist accounts of the nature of the cognitive sciences were always available, identifying the target domain as flexible, more or less intelligent action, feeling, and thought of all kinds. As well as a range of philosophical debates arising out of the materialist consensus, we examine here both the core representational and computational theories of mind, and a number of alternative movements. We deal with general questions about topics relevant to many aspects of our mental life, such as consciousness and causation, with the newly diverse foundational theoretical frameworks in cognitive science, and with a number of particular capacities and psychological domains. 
First, then, we look in some detail at the mainstream debates about consciousness and physicalism which arose directly out of the earlier history of Australian materialism. We cover the influential arguments of Jackson and Chalmers, then a broader array of work on consciousness, selfconsciousness, and mental causation. In the second part of the chapter, we work through the driving theories in cognitive science from its outset, through classical and connectionist versions of the computational theory of mind, and on to ideas about dynamical and extended cognition. Finally, and more briefly, we address a number of key issues or special topics with tight links to that history of foundational theories in cognitive science, looking at folk psychology and theory of mind, delusions and philosophy of psychiatry, and then discrete topics such as emotion, perception, and memory.

\#

\# $\quad$ \#

$\#$

$\#$

$\#$

\#

\section{Part I}

\section{Consciousness and the Mind-Body Problem}

Whether or not they have seen philosophy as employing fundamentally different methods from science, philosophers of mind in Australasia have consistently been driven by a perceived need to see how certain features of the world and human existence take their place in the natural world (Stoljar 2010b). Mind is one of the central targets of such enquiry, alongside meaning, modality, and morality. As Nagasawa points out, even 'Australian dualists adopt their version not because they are attracted to a supernaturalistic, spiritual worldview but because, perhaps paradoxically, they are attracted to a naturalistic, materialistic worldview' which they reluctantly amend (2010: 155). Naturalism, however, takes many different forms. There continue to be differing views about the kind of knowledge philosophy seeks, about the existence of analytic truths and their implications for philosophy of mind, and about the roles of conceptual analysis and of intuitions in solving philosophical problems. We start with some of the Australasian philosophers who have attempted to tackle the problem of fitting the mind into the physical world head-on. Can all my thoughts, dreams, hopes, loves, and fears really be merely material? In this section we focus first on those who have argued that consciousness cannot be physical, and on responses to this work. We then focus on some direct theorizing regarding consciousness, and examine discussions of the relation between the mind and the body that do not focus on consciousness specifically.

\subsection{Can Consciousness be Physical?}

The most famous Australasian work in philosophy of mind since 1980 responds to the versions of materialism described in Jack Smart's chapter. We look at two of the leading arguments that consciousness cannot be physical, offered by Frank Jackson and David Chalmers, and at some responses to them.

\section{The Knowledge Argument}

Jackson's Knowledge Argument (1982) is one of the most influential arguments for dualism (Stoljar and Nagasawa 2004). Mary is a colour-deprived neuroscientist. She is locked up in a black-and-white prison, and never sees colours. Nevertheless she manages to acquire 'all the physical information there is to acquire about what goes on when we see ripe tomatoes, or the sky, and use terms like 'red', 'blue' and so on' (Jackson 1982, p.130). What will happen to Mary when she first experiences colours? The answer seems simple - she will finally know what it is like to see colours. But given that she had complete physical information before her release, it seems then that there is more information for her to know than physical information, and therefore that physicalism is false.

One prominent early reply to the Knowledge Argument comes from David Lewis. The core idea is that Mary does not gain new information or knowledge of a new fact upon release: rather, she gains new abilities (Lewis 1990). An ability is knowledge of how to do something, not knowledge of 
something. In particular Lewis claims that knowing what it is like to see red is not factual knowledge about phenomenal redness, but consists in the ability to remember, recognise and imagine the experience of seeing red. It is only if you have tasted Vegemite that you have the ability to imagine your response to a mouthful of Vegemite ice cream. Knowing what Vegemite tastes like consists (partly) in this ability. If what Mary gains are these abilities, then her pre-release factual knowledge is complete and physicalism is safe.

In his 1986 paper Jackson responds to this ability reply. He insists his core claim is that Mary's new knowledge is about a new fact (p.293). He admits that upon release Mary may gain various abilities. But he denies that this is all that she gains. In particular he claims that she gains new factual knowledge about the phenomenal qualities of other people's experiences. Interestingly, given his later change of heart (see below), he admits that he has no proof that Mary gains knowledge of a new fact. But he claims that he has provided the best that one can expect in this area of philosophy, namely a valid argument from highly plausible premises.

Arguably the most popular reply to the Knowledge Argument is to accept that Mary gains factual knowledge, but deny that this knowledge is about a new fact. The challenge for such 'old-fact' replies is to develop an account of Mary's new knowledge which accounts both for why she cannot gain this knowledge prior to her release and also for why it is nevertheless knowledge of a fact that she knew prior to her release. Bigelow and Pargetter (1990, 2006), Pettit (2004), and MacDonald (2004) have developed versions of this reply.

Bigelow and Pargetter (1990) claim that what Mary gains upon release is new knowledge by acquaintance of a fact that she knew prior to her release. Knowledge by acquaintance provides an epistemically direct way of knowing. For example, although you may know all of the facts about Brad Pitt or Daniel Dennett, unless you have actually met them there seems to be a sense in which you do not know them. You are not acquainted with them. So there is a sense in which Mary gains new knowledge. But this knowledge is not of a new fact: it is just a new, more direct way of knowing facts that she knew prior to her release.

Pettit (2004) provides a different analysis of the new way of knowing that Mary gains. He accepts that Mary's new knowledge is factual, but denies that it provides knowledge of a new fact. Pettit argues first that experiences (he uses the example of motion experiences) represent perfectly physical facts, and secondly that they do not also provide knowledge of (potentially non-physical) phenomenal facts. The second claim is the more controversial. He argues that there is nothing to our experiences beyond their representational content, because whenever the representational content of an experience is changed so too is its phenomenal quality. This is roughly the position that Jackson now holds (see Jackson 2009 for an account of the similarities and differences between their positions).

Finally, MacDonald (2004) argues that concepts, including our concept of red, have modes of possession, and that it is a visual mode of possession of the concept red that Mary is missing. But, MacDonald argues, it would be a mistake to think that these different modes of possession underlie different concepts. This is because concepts are individuated by what they function to identify, not the means by which people identify and re-identify the object of the concept. So upon release Mary gains a new conception, but not a new concept.

The newest line of response to the Knowledge Argument is to embrace the claim that had previously only been accepted by dualists, namely that Mary gains knowledge of a new fact (Schier 2008). Daniel Stoljar suggests (2001) that there are two distinct conceptions of the physical, and that once one is clear about which conception is in use, the knowledge argument fails. There is no one 
conception of the physical on which it is true both that Mary knew all of the physical facts prior to her release and that this means that physicalism is false. The key to Stoljar's response is the claim that scientific theories cannot tell us about the categorical bases of dispositions, but only about the dispositional properties themselves (Stoljar 2001, p.258). However these categorical bases are properties of paradigmatically physical objects and so in learning about them Mary is not learning a non-physical fact.

Finally we consider Jackson's new position. Although the details are new, essentially Jackson now supports an ability reply. What Jackson adds is a representational account both of the mistaken intuition that Mary gains knowledge of a new non-physical fact and also of knowing what an experience is like. Jackson now claims that we are under an illusion about the nature of colour experiences that makes the intuition that there are facts about colour experiences that are not a priori deducible from physical facts look true.

Like other representationalists, such as Pettit, Jackson denies that the phenomenal qualities of an experience outstrip its representational content (Jackson 2004a). So experiences do not represent some new non-physical fact. This is not because they represent some physical fact that Mary knew before her release. Rather this is because they are mis-representations. Like my thought that there is a pig flying around the room, they do not correctly capture the state of the world. So what Mary gains upon release, Jackson concludes, is a new representational state. She does learn what it is like to see red. But it is a mistake to think that this new knowledge is factual. The new representational state is a misrepresentation: there is no property that corresponds to the way it represents the world as being. Instead, what Mary gains is only the ability to have this representational state.

\section{The Hard Problem}

David Chalmers' work on the hard problem of consciousness and his resulting "naturalistic dualism" is a prime example of the way in which Australian philosophers amend their naturalistic worldview in order to accommodate problematic phenomena (Nagasawa, 2010: 155). Chalmers aims to find the middle ground between functionalistic reductionism (which explains phenomenal consciousness in terms of something else) and mysterianism (which claims that it is impossible to understand consciousness). At the center of his argument is the division of the problem of consciousness into easy and hard problems (Chalmers 1995; Braddon-Mitchell 2003; Albahari 2009).

The easy problems of consciousness are those that concern the objective aspects of consciousness and are amenable to functional explanation (Chalmers 1995). As Chalmers points out, 'consciousness' is used in many different ways. For example many consciousness researchers are interested in how information from many sources is integrated into one coherent experience and thereby made available throughout the cognitive system. Although explaining the availability of information is a difficult task, it does not present a fundamental mystery, and in fact good progress has been made on the problem (Baars 1988). In contrast it seems that we have no way to even think about how to fit phenomenal consciousness into the world. It presents a hard problem because it seems that we could be psychologically the same in all other respects, and yet have no conscious experiences whatsoever. Experiences therefore don't seem to do anything and so don't seem to be amenable to a functional, computational analysis. Where easy problems are problems about the explanation of functions, the hard problem is not. We don't know why certain cognitive tasks are accompanied by phenomenal experiences; it just seems to be a brute fact that they are.

But, argues Chalmers, phenomenal consciousness is not the only phenomenon that seems to be basic, that is, which cannot be explained in more fundamental terms. This is also the case for some entities in physics such as space-time, mass and charge. Chalmers argues that consciousness needs to be added to this list; that alongside the basic physical laws we also need to add basic 
psychophysical laws that specify how some physical systems are also conscious $(1995,1996 a)$. Chalmers suggests that information may be the key to understanding the link between the phenomenal and the physical. He notes that the structure of consciousness is mirrored in the structure of information in awareness. For example it is known that phenomenal colour can be ordered in a three dimensional space, with similar colours, such as red and pink, near each other, and dissimilar colours, such as blue and yellow, further away from each other. Although the details are not yet clear, it seems that this three dimensional structure is mirrored in the structure of the processing in the visual system. Chalmers suggests that these observations hint at the hypothesis 'that information, or at least some information, has two basic aspects: a physical one and an experiential one' (1995:99).

Finally a number of Australasian philosophers have worked on developing and defending modal arguments for dualism, the focus of which is consciousness. David Chalmers (1996) argues that unlike other scientific identities, the identity of phenomenal consciousness with something physical cannot be knowable a posteriori because how our experiences appear to us is not a contingent feature of them. Daniel Stoljar argues against 'a posteriori physicalism', and claims that we cannot explain the apparent contingency of the identification of consciousness with the physical in terms of a failure of imagination (2000, 2006; Doggett and Stoljar 2010).

\subsection{Explaining Consciousness}

Many philosophers put aside metaphysical concerns about materialism in favour of constructive theorizing about consciousness. This ranges from examining difficulties facing existing scientific studies of consciousness, to developing explanations of particular conscious experiences, to considering whether consciousness is unified.

\section{Challenges Facing Scientific Explanation}

In this section we consider debates about the scientific explanation of consciousness. Unlike the debates regarding the knowledge argument and the hard problem, the focus here is not on the possibility of a scientific explanation of consciousness. Rather the concern is with current scientific research programs and methods, and the problems they face. For example, one prominent approach to the scientific study of consciousness is the search for the neural correlates of consciousness (NCC). The basic idea is that there will be a difference in brain activity when a person is conscious and is not conscious. Chalmers, Tim Bayne, and Jakob Hohwy have contributed to an ongoing debate about the validity of the NCC approach. Chalmers (2000) clarifies the concept of an NCC and examines the implications this has for the study of consciousness. Perhaps the most important of his claims is that lesion studies are 'methodologically dangerous' because, for example, brain architecture can change after a lesion. Chalmers himself sees the primary task of a science of consciousness as the attempt to integrate first-person data about experiences with third-person data about behavior and neural processes, whether or not any reductive relation exists between these sources of data (Chalmers 2004, 2010). Bayne (2007) warns of the dangers of a mistaken conception of the structure of consciousness in the work on NCCs. He argues in favour of a field conception of consciousness, against the assumption that consciousness has a building block structure, on which he suggests much work in the NCC style is based.

Hohwy (2009) expresses concerns that the current experimental techniques used in the search for the NCC have fundamental and underappreciated problems. He draws a distinction between two approaches to finding the NCC. Work on the NCC for content consciousness focuses on what is required for a specific content to become conscious. In contrast, the state-based approach to the NCC aims to find what is required for a creature overall to be in a conscious as opposed to an unconscious state. Hohwy's concerns with the content-based approach stem from its background 
assumption that the subject is in an overall conscious state. If a researcher assumes that all subjects in their study are conscious, then it is always possible that their experimental manipulations are not getting at what causes a content to be conscious or not. It may be that the content is conscious only because the subject is already in a conscious state, and not because of the content-specific neural changes that are observed. So what the contrast in content-based experiments enables us to understand is what selects a content for conscious experience, not what makes it conscious per se.

Despite these concerns, Hohwy does not think we should reject the content-based approach, because he thinks the state-based approach is equally flawed. Many studies in this vein keep content constant and examine neural activity with or without consciousness. But, as Hohwy points out, the more content is matched in the conscious and unconscious conditions, the more likely we are to say that the supposed unconscious subject is actually conscious. Given these problems with both approaches, Hohwy concludes that we need a 'new type of experimental approach that targets the presumably causal, mechanistic interplay between content processing and overall conscious state across different contents and across different types of conscious and unconscious states' (Hohwy $2009: 435 ; 2010)$. A related controversy about the logic and interpretation of results from neuroimaging has been initiated by Max Coltheart. Coltheart presents a set of explicit criteria for determining whether functional neuroimaging has told us anything about cognition or the mind. He suggests that, to do so, a neuroimaging study or research program would need to offer evidence in favour of one cognitive theory which is inconsistent with the predictions of an alternative cognitive theory. He then argues that, to date, no existing studies meet these criteria (2006a,b, 2010; compare Coltheart and Langdon 1998; de Zubicaray 2006).

Another problem that currently plagues the scientific study of consciousness is the supposed inability to operationalise phenomenal qualities independently of cognitive accessibility (Block 2007). This is a problem because it is currently an open question as to whether there are unaccessed phenomenal qualities. Levy (2008) has argued that, contrary to Block, phenomenal consciousness does not overflow access. He claims that the notion of, say, unfelt pain, is bizarre, and that the evidence that Block presents is insufficiently persuasive to motivate us to accept it. The hypothesis that phenomenology does not overflow access is equally able to explain the data.

The problem that the scientific study of consciousness faces when it comes to the access/ phenomenal distinction is that, currently, the only way to know what an experience is like is to ask the subject. That is, all phenomenal states that we can currently study are also accessed. So it seems that it is not possible to get data speaking to the purported independence of phenomenal qualities from access. Schier (2009) has recently reviewed and defended a suggestion regarding how to find evidence that phenomenal qualities are independent of access (compare O'Brien and Opie 1999a). If we can find evidence that there are neural structures that are isomorphic to phenomenal spaces then we will have found evidence to support their identity. The goal would be to find an area, say, in the visual system where the relations between patterns of neural activity resemble the relations between phenomenal colours. So we would hope to find that the pattern of activity that represents blue is more like the pattern that represents turquoise than the one that represents red.

Importantly, the evidence for the identity is the similarity of the neural activity and colour space. The fact that colour space (and all phenomenal spaces) are measured by asking the subject becomes irrelevant.

\section{Explanations of Consciousness}

Australasian philosophers have developed theories of consciousness in general as well as theories about particular types of experiences. 
Gerard O'Brien and Jon Opie have developed and defended a connectionist, 'vehicle theory' of consciousness (1997, 1999a, 1999b, 2001). They suggest that the cognitive scientist can view mental phenomena such as consciousness as involving two basic things - representational vehicles and the processing of these vehicles. So the cognitive scientist has two basic ways of explaining consciousness. They can either conceive of consciousness as a feature of the representational vehicles, or as a feature of the processing of these vehicles. O'Brien and Opie (1997) term these vehicle and process conceptions of consciousness respectively.

O'Brien and Opie argue that we should adopt a vehicle theory of consciousness if we want to avoid epiphenomenalism about phenomenal qualities. The problem is that the process theorist identifies consciousness with the information-processing effects of the vehicles within the system: what makes a vehicle part of a conscious process is what it does in the wider cognitive system. But, they argue, identifying consciousness with information processing effects means that consciousness cannot be a causal factor in bringing about those effects (O'Brien and Opie 1997). So we cannot, for example, say that I give the verbal report that the ripe tomato in front of me is red because I have a visual experience with the phenomenal quality redness. Rather, giving the verbal report is part of the set of effects that constitute the phenomenally red experience. The worry with this is that it would therefore render phenomenal experiences epiphenomenal in that they do no causal work. In contrast, a vehicle theory takes phenomenal qualities to be a property of the representing vehicles, independently of their effects on the system. This means that the vehicle theorist is not forced into epiphenomenalism. One can report that the tomato is red because of one's experience, because the experience has the property phenomenal redness independently of its computational effects, such as causing such a verbal report. So, O'Brien and Opie argue, it is only if we adopt a vehicle theory that the phenomenal quality of experience can play the explanatory role that we normally assign to it.

So far our discussion has addressed consciousness in general. What makes a subject conscious? What is the difference between conscious and unconscious mental states (Armstrong 1991)? However another branch of consciousness research focuses not on explaining consciousness per se, but on explaining particular conscious experiences, such as the feeling of being in control of one's bodily movements, or the experience of red. Work on understanding the various feelings that underlie self-consciousness began with Frith's work on the sense of agency (1992; see also Hohwy and Frith 2004; Hohwy 2007; Hohwy and Paton 2010, and our discussion of delusions and psychopathology in Part III below). The sense of agency is the sense that you are in control of your bodily movements. Compare how it feels to kick your leg voluntarily with how it feels for your leg to move when it is hit on the knee. In the first case it feels like you did the moment whereas in the second it doesn't. You have a sense of agency for the voluntary, but not for the reflex action. Bayne has worked with a number of researchers on the sense of agency. With Pacherie (Bayne and Pacherie 2007), he argues that a full account of our sense of agency will involve an appeal to both a domain-general narrative system and a low-level domain specific comparator system. They suggest that judgments regarding our agency will appeal to an agent's narrative self-conception, and that the sense of agency will be explained by the comparator mechanism that is responsible for actionproduction. Bayne and Levy (2006) examine the phenomenology of agency. They argue that the experience of agency has a number of distinct experiences as components, including the experience of mental causation, the experience of authorship, and the experience of effort. Based on this analysis they argue that those such as Wegner (2002), who think that the current cognitive science suggests we don't have free will, are working with a naïve conception of the phenomenology of agency. A more sophisticated understanding of the phenomenology of agency may help reconcile the data with the claim we have free will (Bayne 2006; compare Carruthers 2010). 
Glenn Carruthers $(2008,2009)$ has developed an account of the sense of embodiment. Although you probably don't pay it much attention, you feel like you are bounded in your body; that you have edges that normally correspond to the edges of your body. Carruthers suggests that our sense of embodiment arises from an offline representation that represents the body as an integrated whole. He argues that we can see the role of offline representations of the body in constructing our sense of embodiment by considering body integrity identity disorder (BIID: see also Bayne and Levy 2005). People with BIID have a long-standing stable desire to have one of their limbs amputated. These people report that they want their limb amputated so that their body will fit their 'true' self - they feel like the limb is not really part of them. Despite this, they have no problems sensing the limb or controlling it. Carruthers suggests that this demonstrates that they do have intact representations of their body in the moment: the problem is with the more long-term, offline representation of the body. This is a different approach to the problem of consciousness: instead of explaining consciousness in general, the goal is to give an explanation of why people with BIID feel embodied in a different way to normal people and therefore why their experiences are like what they are like.

\section{Unity of Consciousness}

At any one time we have a diverse range of conscious experiences. For example right now you can see the page in front of you and feel the chair (or the sand of the beach) against your body. These distinct experiences all occur at the same time: but are they in some sense unified into an allencompassing experience? Or is there just a collection of diverse experiences whose only unity is that they happen to be occurring together?

But what exactly does it mean to say that consciousness is unified? Australasian philosophers differ on how to answer this question. O'Brien and Opie $(1998,2000)$ suggest that the unity or disunity of consciousness is best understood as a claim about the nature of the "consciousness-making" neural mechanisms. If there is a single consciousness-making mechanism then consciousness is unified, if there are many, then it is disunified. Bayne (2000) takes issue with this definition of the unity of consciousness. He suggests that what is taken by many people in the debate to be at issue is not the nature of the mechanism but rather whether all of a subject's experiences are part of a single global experience. While O'Brien and Opie agree that this notion of the unity of consciousness exists, they suggest that it does not hold up to scrutiny. The problem is that in talking about experiences being unified in a single experience the definition entails that phenomenal consciousness is both plural and singular.

O'Brien and Opie argue that evidence for the disunity of consciousness comes from the distributed nature of the mechanisms responsible for consciousness. So, for example, the neural architecture responsible for the processing of motion is distinct from that which is responsible for processing colours, such that it is possible to lose one capacity while the other stays intact. This suggests that the mechanisms that produce experiences of motion and of colour are distinct. The problem with this argument is again that the data is interpreted differently by those who hold a different theoretical position. Bayne (2000) points out that those who claim that consciousness is unified need not be committed to the claim that there is a spatially localized consciousness-making mechanism in the brain. Instead they could claim, for example, that consciousness is produced by temporal synchrony across a range of mechanisms.

Tim Bayne has done a range of further work on the unity of consciousness, including a recent book (2010). Here we focus on his argument that 'split brain' data does not threaten the phenomenal unity of consciousness (Bayne 2008). A split brain patient has had the sub-cortical connections between their hemispheres severed. (Following Bayne we use the term 'split brain' to cover both commissurotomy, which involves severing a number of interhemispheric tracks, and callosotomy, in which only the corpus callosum is severed). Such patients behave almost entirely normally in 
everyday situations. But in controlled laboratory conditions some bizarre behavior emerges. The standard type of experiment involves presenting different information to each hemisphere (by presenting different information to each visual field). So the left visual field (and therefore right hemisphere) may be shown the word 'key', and the right visual field (and therefore the left hemisphere) will be shown the word 'ring'. What is interesting is what happens when such subjects are asked to report what they saw. For most people language is localized to the left hemisphere. So when asked to verbally report what they see, they will say they saw a ring. But when the non-verbal right hemisphere is asked to report what it sees (by getting people to point with their left hand) it will report that it saw a key. It seems tempting to say that these people have a disunified consciousness, that their left hemisphere is conscious of the word 'ring' and that their right hemisphere is simultaneously conscious of the word 'key'.

However, as Bayne points out, they aren't as disunified as the standard type of presentations, such as that given above, would suggest. For example, although patients cannot integrate information concerning shape, colour and category across the two sides of their visual field, they can integrate information about relative motion and size of visual stimuli. Moreover, as mentioned earlier, these patients do not appear to have a disunified consciousness in everyday circumstances. Bayne argues for a 'switch' model: consciousness switches between the patient's two hemispheres, but at any one time only one hemisphere is conscious. As Bayne points out, no data speaks to simultaneous but separate consciousness in both hemispheres. Instead at one point in time the patient shows awareness of the ring by talking about it, at another point in time they show awareness of the key by pointing to it. Earlier work on the perception of chimeric figures by split brain patients (Levy et al 1972) further suggests that their consciousness switches between their hemispheres. Subjects were shown figures that were split down the middle, such as an image where the left side was a picture of 'Bob' and the right side was a picture of 'Peter'. They were asked to name the person it was a picture of. They found that at any one time only one hemisphere responded and that there was no indication, either in terms of words or facial expression, that the other hemisphere disagreed. Instead it seemed like at one point in time they were conscious of one half of the picture, and at another point in time they were conscious of the other half.

\subsection{General Worries about the Mind-Body Problem}

The development of the computer model of the mind has enabled us to see how thought could be produced by a purely physical device (see Part 2 below). This is why so much of the debate about how the mind could relate to the body now focuses on consciousness. Despite this general proof of principle for thought there are still a range of concerns about the relation of the mind to the body that do not appeal specifically to consciousness.

At the heart of the problem of mental causation is the worry that the claim that mental states supervene on physical states is incompatible with them being causally efficacious. The problem is that physical states seem to have entirely physical causes and effects. And so there seems to be no room left for the somehow more than physical mental states to do any causal work (Kim 1998). A number of solutions to the problem of mental causation have been proposed.

Jackson and Pettit $(1988,1990 a, 1990 b)$ argue that it is a mistake to think that only causally efficacious properties are relevant in causal explanations. They argue that certain causally inefficacious properties play a crucial role in causal explanations. In particular, properties can causally program without actually causing $(1988$, p.394). They ask us to consider for example how we would go about explaining why two electrons accelerate at the same rate. To do so we would say that the forces acting on them are of the same magnitude. But equality of magnitude per se is not something which actually causes the electrons to move: rather the individual forces acting on the 
electrons do the causal work. Jackson and Pettit suggest that we appeal to such causally inert properties because these properties remain constant under variation. For example if we were to appeal to the causally efficacious property in the electron example we would have to talk about the precise magnitude of the force. And so we would lose sight of the fact that what matters is not the actual magnitude of the forces, but rather their equality. Jackson and Pettit argue that the equality of the forces programs for the equality of effects even though it does not cause it. Program explanations are, they argue, a viable and necessary alternative to process explanations, which are explanations in terms of the causally efficacious properties (see also Bliss and Fernandez 2010). If we are to give up on program explanations then we must dismiss all the perfectly good explanations offered by the special sciences, and even those offered by physics that involve reference to an indeterminate number of things (Jackson and Pettit 1990b, p.112). For example they suggest that an explanation of the formation of water vapor near the surface of water in terms of the fact that some of the molecules have broken free would be inadequate because it does not capture the particular molecules that are doing the causal work in any particular instance. Instead it captures the general mechanism that all these instances have in common. Finally they argue that type identity and supervenience responses to the problem of mental causation fail (1990a). Instead they suggest that functional properties are crucial in explanations because they enable us to capture not only how something in fact came about, but also the various other ways it could have come about (but see Jackson 1996 for a different earlier approach to mental causation).

Pettit has also worked on understanding what physicalism requires. He argues that we can get a non-trivial and not obviously false definition of physicalism if we centre an account around two claims: first of all that the world is built out of materials that physics is in the best position to identify, and secondly that the world is governed by regularities or forces that physics is best positioned to describe (Pettit 1993, p.213).

Cynthia and Graham MacDonald argue that accounts such as Pettit and Jackson's, which accept that mental properties are only causally relevant and not efficacious, lead to the explanatory redundancy of the mental. This is because 'if there is no distinctive pattern at the psychological level, then there is nothing for the psychological properties to explain' (Macdonald and Macdonald 1995, p.61; 2006; 2007). So they find the program explanation solution unsatisfactory. However they think that nonreductive materialism can be saved. The details of their position take us into 'hard-core' metaphysics, regarding the weaknesses of a trope conception of events and properties and the compatibility of a particular type of property exemplification view with non-reductive materialism, that are beyond the scope of this chapter.

Peter Menzies $(1988,2003,2007)$ argues against the sort of causal reductionism offered by Kim and others. He suggests that the problem in the problem of mental causation is our conception of causation. In particular he claims that in discussions of the problem, causation is viewed as a categorical absolute relation when in practice we take causal relations to be 'entities occupying certain functional roles that are defined with respect to abstract models' (2003, p.196). Importantly, if we understand causation in terms of models then different models may be operating at different levels: these models and the causal relations they appeal to need not be in competition. Other philosophers who have discussed reduction with relation to the philosophy of mind include Ravenscroft (1998) and Gold and Stoljar (1999; see also Hohwy and Kallestrup 2008).

Unlike the other philosophers we have considered in this section, Cliff Hooker is a radical naturalist. He attributes this to his physics training, which taught him that we can easily form erroneous conceptions of the seemingly everyday and obvious (Hooker 2006). A detailed treatment of his works belongs in a discussion of philosophy of science, but it is worth noting that one's 
understanding of reduction is going to directly influence one's views on the possibility of a reduction of the mind to the brain (Hooker 1981, 2004, 2006).

Part 2

\section{Foundations and Frameworks for Cognitive Science}

In addition to their work on the metaphysics of mind, and often in close connection with it, Australasian philosophers contributed directly to debates on the foundations of cognitive science. In ongoing dialogue with computational modellers and Artificial Intelligence researchers, and with philosophers such as Block, the Churchlands, Dennett, Dretske, Fodor, Putnam, and Searle, they joined the search for an understanding of how meaning can be realized in matter, developing and interrogating the computational theory of mind (СTM). We can understand CTM, at its most general, as the claim that cognitive processes are computational processes, where computational processes are causal transitions between contentful states which preserve or reflect semantic relations. Proceeding more swiftly and lightly here than in Part I, we examine first the very idea of the mechanisation of mind in the form of such a computational theory, then its classical and connectionist versions, before discussing more and less radical extensions of or departures from that theory in ideas about embodied and extended cognition.

\subsection{Cognitivism, computation, and content}

Before discussing recent versions of the computational theory of mind, we note some contributions to the history of cognitive science. Elizabeth Wilson (2010) unearths a surprising depth and sophistication in the discussions of emotion and affect in the work of Alan Turing, Walter Pitts, and other pioneers of Artificial Intelligence. Likewise, Jack Copeland's extensive work on the history and philosophy of computing has shown how broad and original were Turing's theoretical and philosophical contributions. As well as identifying, editing, and interpreting a large body of neglected primary material by and about Turing (Copeland 2004, 2005), Copeland has revivified interest in Turing's work on nonclassical computability (Copeland and Sylvan 1999), argued that Turing anticipated key ideas of connectionism (Copeland and Proudfoot 1996), and corrected prevalent misunderstandings of the Church-Turing thesis (Copeland 1997). Turing's wider views on the idea that the mind is a machine (Copeland 2000a) have been discussed most in relation to the Turing Test for machine intelligence (Copeland 2000b; Proudfoot and Copeland 2009; Oppy and Dowe 2011) and John Searle's Chinese Room argument against machine intelligence (Cam 1990a; Chalmers 1992; Copeland 2002; Tanaka 2004; Coutts 2008). Both Chalmers (1994/ 2012, 1996) and Copeland (1996) develop foundational accounts of the nature of computation which respond to the charge made by Putnam and Searle that every physical system implements every computation. Identifying a number of ways in which finite-state automata can be implemented in a physical system, Chalmers shows that 'the implementation relation between abstract automata and physical systems is perfectly objective', such that 'computational descriptions of physical systems need not be vacuous': he argues for a kind of generic or 'minimal computationalism', 'compatible with a very wide variety of empirical approaches to the mind'.

Such computationalism was taken by Fodor and others to vindicate our ordinary or 'folk' intentional realism, our attribution of intentional states which both have causal powers in driving our actions and are semantically evaluable. Computational processes, on this view, are causal transitions over mental representations. For some time, the most detailed account of how such computational processes might be realized was offered by the Language of Thought Hypothesis (Fodor 1975). The brain contains discrete language-like symbols, in 'Mentalese' rather than natural language, each of which can both be non-semantically identified (in virtue of their form or syntax) and reliably 
interpreted. An inner 'code' specifies legitimate forms of combination and recombination of these representational 'atoms' in the same way that words combine into sentences. Mental processes are causal processes requiring the explicit tokening of each relevant symbol (Fodor 1987; Sterelny 1983, 1991 ch.2). Like the Turing Machine, the mind-brain is a device which supports and manipulates these discrete functional elements according to appropriate rules or programs.

As well as independent critical analysis of the Language of Thought hypothesis (Sterelny 1989b; Braddon-Mitchell and Fitzpatrick 1990; Maze 1991; Braddon-Mitchell and Jackson 2006), by the mid1980 s a quite different way of developing the computational theory of mind had emerged with the rediscovery of connectionism or 'Parallel Distributed Processing'. Cognitive processes, for the connectionist, are processes of pattern-recognition and pattern-transformation. Mind is not text but process: enduring mental representations are not stored as discrete symbols, but holistically as distributed representations across the weights of a multi-layered neural network. In early work on the nature and capacities of connectionist systems employing such distributed representations, Chalmers (1990) and van Gelder (1990; van Gelder and Niklasson 1994) responded to Fodor and Pylyshyn's charge that these networks had insufficient structure to exhibit certain alleged characteristics of cognitive systems, explaining in detail how connectionist systems could evolve unique forms of structure-sensitive processing (also Garfield 1997). Developing a fuller taxonomy of forms of representation, van Gelder defined distribution in terms of semantic superposition, where many items are represented within one representation, criticizing the Language of Thought and synthesizing evidence that 'representation in the brain is distributed' $(1991,1992)$.

Although connectionism is still (on most interpretations) a computational theory of mind, in that distributed representations too carry content, it has a very different flavour. Learning is a continuous process of adjustment to the overall system rather than the addition of new symbols; generalization, abstraction, and automatic updating are intrinsic features of processing; 'storage' involves the transformation rather than the preservation of information; and remembering is therefore the reconstruction of a similar pattern of activation rather than the reproduction of a stored item (van Gelder 1991). These features were taken by some to promise dramatic new accounts of memory, self, truth, and cognitive discipline (Sutton 1998a, Wilson 1998). The root of such properties, argued O'Brien (1999), lies in the analog nature of computation in distributed connectionism. Unlike digital computers in which abstract symbols are arbitrarily related to their representational domains (a point which allied classical cognitivism with functionalism, on which see Jack Smart's chapter in this volume), analog computers directly or physically manipulate 'analogs' of their representational domains. As O'Brien puts it, 'a material substrate embodies an analog of some domain when there is a structural isomorphism between them, such that elements of the former (the representational vehicles) resemble aspects of the latter (the representational objects)'. With Opie, O'Brien has gone on to develop a representational and computational analysis of neural networks in terms of resemblance (O'Brien and Opie 2001, 2004, 2006, 2009). They argue that the content of both activation pattern representations and connection weight representations is grounded in this structural resemblance. While Paul Churchland (1989) had suggested that activation patterns systematically resemble what the network is representing, he did not analyse the intra-network processing which gives rise to these output patterns: O'Brien and Opie $(2006,2009)$ offer the first analysis of the computational and representational capacities of distributed networks by reference to the structure and functions of connection weights.

In invoking mental representations, cognitivists also required an account of the origins of meaning: how can a representing vehicle be about its represented object? Within a broadly computational framework, which symbols have 'meaning for the machine' (Clapin 1995, 2002)? This is the job of a theory of content determination (TCD). Australasian work has focused on teleological and resemblance TCDs. Teleological TCDs developed as a response to problems with Fodor's causal TCD 
and with informational semantics (Godfrey-Smith 1989). In such theories the distinction between accurate representation and error depends on the notion of biological function. So a vehicle 'represents when the token is caused by circumstances of the same kind as those selectively responsible for the existence of the type' (Sterelny 1990, p.124), and misrepresents when not caused by the circumstances for which its type was selected. On the one hand, the development of teleological TCDs has been a key area of overlap between philosophy of mind and topics in the philosophy of biology which are also discussed elsewhere in this volume (Sterelny 1983, 1990; Godfrey-Smith 1992, 2006; Brown 1993; Neander 1995, 1996, 2006; Braddon-Mitchell and Jackson 1997). On the other hand, because they treat historical factors as constitutive, teleological TCDs also played a central role in discussions of whether content was 'narrow', that is, independent of the world outside the individual), or 'wide', that is, partly dependent on factors outside the individual (Jackson and Pettit 1988, 1993; Devitt 1989; Jackson 2004b).

O'Brien and Opie, in contrast, have developed a structural resemblance TCD. Resemblance TCDs are usually dismissed because the mind is capable of representing many more things that it resembles: I can represent the green leaves on the trees outside my window even though my brain is not green. But, building on parallel ideas in aesthetics (Files 1996), O'Brien and Opie point out that there is a more abstract 'second-order' notion of resemblance. In second-order resemblance, 'the requirement that representing vehicles share physical properties with their represented objects can be relaxed in favour of one in which the relations among a system of representing vehicles mirror the relations among their objects'. Things can share a pattern of relations 'without sharing the physical properties upon which those relations depend'. So my brain can represent green by structural resemblance without having to be green itself. In line with their connectionist view of analog computation, O'Brien and Opie take content to be grounded in the physical relations between representing vehicles. In general, 'one system structurally resembles another when the physical relations among the objects that comprise the first preserve some aspects of the relational organization of the second'.

\subsection{Dynamics, Robotics, and Embodied Cognition}

Among philosophers who were initially enthused, in the late 1980s and early 1990s, at the prospect that connectionism might ground a new and general approach to cognition, some grew impatient with the nature and rate of conceptual change. In radicalising further, hoping to arrive at a cognitive scientific route to 'post-Cartesian agency' (van Gelder 1995:379-381), they turned to dynamical systems theory, inspired by new movements in developmental psychology and roboticss as well as older ideas from cybernetics and phenomenology. The concepts and language of dynamical systems were already in use to describe continuous-time recurrent networks (CTRNs) in computational neuroscience and in early Artificial Life research, and a few philosophers in the early 1990s saw that the new sciences of complex dynamics might pose specific challenges for understanding the mindbrain (Foss 1992). Hooker and colleagues (1992) had taken Watt's steam engine governor as a model control system and argued for a fundamental integration of dynamical control theory with connectionism. But the revolutionary version of dynamicism in philosophy was primarily driven by Tim van Gelder $(1995,1998)$. For van Gelder, cognition is a continuous process of state-space evolution in a time-sensitive dynamical system. When such systems are densely interconnected, with the values of their component variables interdependent, they are 'complexes of continuous, simultaneous, and mutually determining change' (1995:373). This notion of 'coupling' by way of 'continuous reciprocal causation', in which variables mutually determine each other's changes, lies at the heart of the suite of dynamical and situated approaches to cognition which have gained adherents over the past 15-20 years (Clark 1997:165).

In van Gelder's coedited collection of empirical studies in dynamical systems approaches to cognition, Mind as Motion (1995), this constructive dynamical vision was put into practice in models 
not only of perception and motor skills, but also of decision-making. But van Gelder also argued, in critical mode and more controversially, against the existing theoretical foundations of cognitive science. Classicist and connectionist versions of the computational theory of mind, in his later view, share significant errors. They unnaturally separate inner cognitive processes from perception and action (an error which Susan Hurley [1998] would label 'the classical sandwich'). They envision the temporal embedding of cognition in discrete steps or updatings, rather than in the unfolding dynamics of continuous trajectories in real time. Finally, they either focus solely on, or still unnecessarily privilege, discrete representational states. Each of these criticisms has led to ongoing debate, perhaps most notably with a different group of post-connectionist philosophers, led by Andy Clark, for whom the tools and concepts of dynamical systems theory should be entirely compatible with more liberal accounts of representation and computation (cf Christensen and Bickhard 2002; Christensen and Hooker 2004).

Parallel and related discussions occurred among philosophers impressed with new developments in robotics. The two roboticists whose work has unarguably influenced philosophy most thoroughly in the last 20 years both took their first degrees in Australia: Rodney Brooks in Mathematics at Flinders, and Barbara Webb in Psychology at Sydney. Addressing a long-standing biological problem - the mechanism of phonotaxis in female crickets, their capacity to detect and reliably move towards a single sound or signal - Webb's robot models showed that adaptive success in this domain requires surprisingly little in the way of discrete internal representations of the location and nature of the sounds to which the crickets respond. Rather, the organized interactions which ground this capacity are spread across the cricket's whole body and its environment. In particular, Webb's biologicallyinspired robots successfully perform their task without any centralised internal model of the incoming stimuli: rather, she suggests, a full-body tracking mechanism responds to the specific temporal pattern of the male cricket song. Webb's nuanced scepticism about the need to invoke the manipulation of mental symbols $(1994,2001,2006,2009)$ perhaps suggests some ongoing influence of the Andersonian direct realist theorists in Psychology at Sydney (see Part 3 below). Rodney Brooks' assault on mainstream cognitive science was more direct: 'explicit representations and models of the world simply get in the way. It turns out to be better to let the world itself serve as its own model' (Brooks 1991). The relatively simple robots or creatures in the influential early work from Brooks' lab at MIT had to do something purposeful in their world, coping appropriately in real time with changes in their environments, and maintaining multiple goals. Complex behaviour emerged from simple interactions between the creature's relatively self-contained subsystems, rather than as the execution of an internally generated plan. Most importantly, the creatures had to be physically grounded, and thus embodied, as well as situated in a real changing world (Brooks 1990). But whereas van Gelder explicitly aligned his anti-representationist dynamicism with the phenomenological tradition in philosophy (van Gelder 1999), Brooks took the trouble to point out that his robotics research 'isn't German philosophy' and 'was based purely on engineering considerations'. He did however accept that it 'has certain similarities to work inspired' by Heidegger, and was connected not only to Artificial Life but also to Varela's approach to autonomous systems (Brooks 1992). In seeking to model perception and 'intelligence without representation', and cognition without central control, Brooks influenced later enactivist attempts to integrate phenomenology and cognitive science (Menary 2006).

Robotics in Australia has continued to flourish, with innovative technical work at a number of centres. Australian philosophers of mind and cognition, however, have not engaged as closely with recent developments as applied ethicists (Sparrow 2009) and cultural theorists (Tofts, Jonson, \& Cavallero 2002; Cleland 2010; Wilson 2010). The Australian performance artist and theorist Stelarc, for example, seeks to extend bodily capacities through robotic and other prosthetic technologies (Stelarc 1991; Smith 2005), in conjunction with roboticists at Carnegie Mellon and Sussex, in work discussed extensively by philosophers such as Clark (2003). In turn, uptake of the specifically 
'embodied' and 'enacted' dimensions of what has become known as the '4E Cognition' movement (for 'embodied, embedded, extended, and enacted' cognition, Menary 2010a) has in Australia been at the heart of interaction between phenomenology and cognitive science (O'Brien \& Diprose 1996; van Gelder 1999). There has been some critical evaluation and development of enactivist and neurophenomenological research (Bayne 2004; Lyon 2004, 2006; Menary 2006), but more attention has been paid in Australasian philosophy to the ideas of embedded and extended cognition, on which we therefore shortly focus. We first note briefly a different connection with the framework of 'embodied cognition', which has sometimes been described at a somewhat abstract level, in links back to philosophical discussions of knowing how, tacit knowledge, and skill. Some work on these topics has been inspired by themes from Wittgenstein and Ryle (Candlish 1996; Melser 2004) or by recent attacks on Ryle (Devitt 2011); other theorists make contact with neuroanthropological and cognitive anthropological approaches to embodiment and tacit knowledge (Gerrans 2005, Downey 2010a,b), with phenomenological views on skills and habit (Wrathall and Malpas 2000; Reynolds 2006; Sutton et al 2011), or with theoretical issues arising directly from consideration of dance, sport, or other bodily practices (Downey 2005; Grove, Stevens, and McKechnie 2005; Davids, Button, and Bennett 2007; Smith 2007; Sutton 2007b; Rothfield 2008; Priest and Young 2010).

\subsection{Extended Mind and Distributed Cognition}

Robert Wilson argued in 1994 that the computational states of cognitive systems need 'not supervene on the intrinsic, physical states of the individual', so that such systems may 'transcend the boundary of the individual and include parts of that individual's environment' (Wilson 1994:352). Rejecting Fodor's methodological solipsism, Wilson reinterpreted a series of results in the cognitive psychology of perception and navigation in claiming that the best taxonomies of certain kinds of computational systems will not be individualistic. Wilson's 'wide computationalism' foreshadowed one of the most-debated ideas in contemporary philosophy of mind, the extended mind hypothesis, which was introduced under that label by Andy Clark and David Chalmers (1998). Clark and Chalmers argued that both occurrent cognitive processes, such as actively remembering the location of a museum, and enduring cognitive states like standing beliefs and memories, are in certain circumstances constituted partly by external, non-biological resources as well as by states of the brain. The symbols which carry reliable information in a notebook, for example, which an agent consistently relies on to supplement biological memory, have just as much claim to be vehicles of cognitive processes as do that agent's neural states. Noting a number of dimensions on which such interactions between agent and external resource can vary, Clark and Chalmers sought to undermine the default assumption that the mind must stop, and the rest of the world begin, at 'the boundaries of skin and skull'.

Clark's book Being There (1997) offered a rich empirical background to the extended mind thesis, synthesizing antecedent ideas in robotics, dynamical systems theory, developmental psychology, phenomenology, philosophy of biology, and cognitive anthropology (see also Hooker 1998; Sutton 1998b). Information technology theorists like Douglas Engelbart had more speculatively articulated related visions in the 1960s: as van Gelder later wrote, 'Engelbart's vision of computers augmenting human intelligence is, properly understood, a vision of human self-transformation through a bootstrapping process in which our current, technologically augmented intellectual capacities enable us to refashion the spaces and practices within which we ontologically self-constitute' (van Gelder 2005,181 ). A more surprising antecedent is a thought experiment considered at one point in Martin and Deutscher's much earlier work on the causal theory of memory (discussed further below). Rejecting the idea that the causal chain between past experience and present remembering 'should continue without interruption within the body of the person concerned', Martin and Deutscher argued that this would make too much of what are contingent features of memory in human beings (1966:181-2): 
We do not want to say that we can conceive only of humans remembering. Surely it is imaginable that we might find creatures who could represent the past as efficiently as we do, in the various ways we do, but who differ from us in the following respects. They carry a metal box around with them and, if they are separated from it, then they can remember nothing, no matter how recent. They are not born with the boxes. The boxes are made in a factory, and given them at birth, after which the creatures gradually develop the ability to remember. They do not ask the box questions about the past, but when they are connected with the box they remember as we do. This case shows that the suggested criterion [that the causal chain should be entirely within the body] is not strictly necessary.

Martin and Deutscher did not go on, as contemporary extended mind theorists do, to suggest that as a matter of fact, human memory does sometimes operate like this: but their thought experiment clearly sets out the key criterion that the coupled interaction between agent and external resource should be sufficiently smooth or transparent. There are not two steps involved: just as I do not ask my brain questions about the past, these creatures do not need to interrogate their external devices. When connected with the box, they 'remember as we do': the box is not first inspected before remembering, but is rather just the means or medium of remembering the past. Just as the creatures can be separated from these boxes, so a notebook could of course be stolen or tampered with: but as Clark repeatedly reminds us, a whole range of mishaps and disruptions (with many different causes) can also befall our brains. The location of memory traces is inessential: what matters is instead their relation to the past experience, and the role they play in driving current remembering (Sutton and Windhorst 2009).

The extended mind thesis might seem to have carried functionalism to a natural conclusion: if mental states are to be identified not by their intrinsic nature but by the roles they play in an interconnected system driving cognition and action, there is no principled reason that those roles cannot be filled in part by external resources. Yet Clark and Chalmers' suggestion that we check for 'parity' of functional contributions across inner and outer resources led critics to think that extended cognition could be refuted by pointing out that the representational format and computational dynamics of internal cognitive systems differed greatly from anything we find in the environment (O'Brien 1998 is a clear statement of this worry; for other critical discussion of the extended mind see Dartnall 2007). This point, of course, was not surprising to philosophers who came to extended cognition by way of connectionism. So arguments for the thesis which do not rely on functionalism and the parity principle have also been developed (and see Chalmers 2008, Drayson 2010 for doubts about the link between functionalism and extended cognition). Sutton characterized a 'secondwave' version of extended cognition based on the 'complementarity principle', the idea that neural and external media with quite disparate properties interface and cooperate so as to transform their particular virtues in a single, larger integrated cognitive system (Sutton 2002a, 2006, 2010a). Richard Menary, whose edited collection of papers from the first international conference on the extended mind in 2001 was launched by Chalmers at the 2010 AAP (Menary 2010b), developed a similar interpretation under the label of 'integrationism', which also drew effectively on the pragmatist tradition and on Vygotsky (Menary 2007). In turn, Wilson expanded substantially on his earlier work in Boundaries of the Mind (2004), which defended and applied extended cognition in sustained discussions of topics such as realization, nativism, intentionality, and social theory. He also collaborated with Clark on an important restatement of the extended cognition view in The Cambridge Handbook of Situated Cognition. As well as responding to criticisms, Wilson and Clark noted that key criteria against which putative cases should be assessed are matters of degree: "the notion of an extended mind is nothing more than the notion of a cognitive extension ... that scores rather more highly on the [dimensions] of durability and reliability" (Wilson and Clark 2009, 66). In such multidimensional frameworks, the agents and artefacts who form enduring or more fleeting coupled interactive systems need not exhibit any kind of functional parity. Attention in the field is perhaps shifting from the attempt to identify the metaphysical boundaries within which cognition is 
located, towards empirical methods for understanding "the dynamics of movement in the [multidimensional] space" and the means by which "resources become individualised and entrenched" (Sterelny 2010, 480).

Clark and Chalmers had also briefly considered the idea of 'socially extended cognition', suggesting for example that in an 'interdependent couple', one partner's mental states may play the right kind of role for the other: 'what is central', they argued, is again only 'a high degree of trust, reliance, and accessibility' $(1998,17)$. The possibility of such socially distributed decision-making, beliefs, or memories, though more central in cognitive anthropology (Hutchins 1995), has been scrutinized in five distinct lines of philosophical discussion: on trust and deception in social-cognitive dynamics (Sterelny 2004; Parsell 2006); on group cognition, collective intentionality, and group agency in social ontology (Miller 2002, 2005; Pettit 2003; Wilson 2004; Pettit and Schweikard 2006); on cognitive history (Tribble 2005, 2011; Tribble and Keene 2011; Tribble and Sutton 2011); on education and pedagogy (Mousley 2001); and on collective and transactive remembering (Wilson 2005; Sutton 2008; Sutton, Harris, Barnier, and Keil 2010).

\#

\#

\#

$\#$

\#

\#

\#

\section{Part 3 Specific Topics in Philosophy of Mind and Cognition}

\subsection{Folk Psychology, Theory of Mind, and Philosophy of Psychiatry}

Alongside this foundational work on cognitive architecture and cognitive processing, Australasian philosophers have also contributed heavily to research on our ordinary capacities to understand each others' actions and minds. These topics, going back to the traditional problem of other minds (Hyslop 1995, 2005), have cycled through several phases under a range of labels from 'folk' or common sense psychology, to theory of mind (ToM) and mindreading, and have been linked with a range of related debates. In making sense of human action and interaction by ascribing beliefs and anxieties, hopes and desires - a psychology - to other people, we seem to employ a subtle and reliable, though fallible, ability to read their minds (Davies and Stone 1995a; Ravenscroft 2009). In a first wave of interest, the Churchlands' claim that folk psychology should and would be eliminated, or at least substantially revised, in light of the growth of cognitive and computational neuroscience, received considerable attention (Campbell 1986, 1993; O'Brien 1987; N. Stoljar 1988). Jackson and Pettit (1990), for example, argued that once the folk conception of beliefs and desires is properly understood, by way of a commonsense functionalist approach, the possibility that it is radically mistaken is highly unlikely. O'Brien (1991) responded to the idea that connectionism might lead to eliminativism by arguing that transient activation patterns do fill the right kind of discrete functional role to match the folk conception of occurrent intentional states, while the causal holism of distributed connectionist networks offered stronger resources for a defence of intentional realism with regard to enduring beliefs. As debate about eliminative materialism and other aspects of the Churchlands' work continued through the 1990s (Stich and Ravenscroft 1992; Sterelny 1993; Gold and Stoljar 1999), however, new debates on 'theory of mind' also emerged.

The eliminativists had shared with intentional realists like Fodor the view that folk psychology is an internalized theory which we deploy to predict and explain other people's behaviour. Despite the availability of a new alternatives in the idea of 'mental simulation' and a new focus on empathy (Davies and Stone 1995b), Australasian philosophers in general continued to defend this 'theory theory' (Jackson 1999). But distinct forms of 'theory theory' were distinguished, often involving distinct conceptions of the nature of cognitive development. In the most controversial approach, theory of mind was described as an innate, encapsulated, and domain-specific module, sometimes within broader nativist agendas. As well as criticism and revision of the conceptions of modularity 
offered by Fodor and by more extreme evolutionary psychologists (Cam 1988; Coltheart 1999; Parsell 2005), Fodor's nativism also received sustained criticism, notably in Fiona Cowie's What's Within: nativism reconsidered (1998; Sterelny 1989). With specific regard to the putative theory of mind or social cognition module, critical responses ranged from the proposal of alternative, more modest forms of modularity (Currie and Sterelny 2000) to more thoroughgoing rejection (Gerrans 2002a; Stone and Gerrans 2006; Gerrans and Stone 2008; Parsell 2009). This literature on the theory of mind module drew in detail on developmental psychology and psychopathology, with particular attention paid to theory of mind in autism, deafness, and Williams syndrome (Gerrans 1998, 2003a; Garfield, Peterson, and Perry 2001; Parsell 2010). Other notable work on theory of mind included Godfrey-Smith's conception of folk psychology as a model $(2004,2005)$, while Reynolds (2010) discussed questions of intersubjectivity and other minds in recent European philosophy.

Constructive philosophical theory-building on the basis of developmental psychology (Griffiths and Stotz 2000; Sutton 2002b) and of studies of animal cognition (Browne 2004; Chadha 2007; Corballis and Suddendorf 2007) overlapped with topics in the philosophy of biology discussed at greater length elsewhere in this volume. It is however appropriate to point here to the relevance for philosophy of mind and cognition of some work in this field. Ideas from developmental systems theory in philosophy of biology were put to use in criticism of existing accounts of innateness and of the 'biologicizing' of mind (Griffiths 2002; Griffiths and Machery 2008). In positive work on cognitive niche construction, the view was developed that human cognition is particularly adapted to hook up with rich environmental scaffolding which we have collectively and cumulatively engineered, including the linguistic, cultural, institutional, and technological resources which augment and transform our cognitive capacities (Sterelny 1992, 2003, 2007; Griffiths 2007; Jeffares 2010; Stotz 2010). Though clearly making contact with the ideas of situated cognition and the extended mind as described above (Sterelny 2010), the philosophers of biology linked the idea of cognitive niche construction more directly to theories of the evolution of cognition (Godfrey-Smith 1996, 2002; Sterelny 2003, 2009; Christensen and Hooker 2002; Christensen 2010). Important contributions to our understanding of the evolution of human cognition and the history of tool use have also come from archaeologists (Noble and Davidson 1996; Davidson 2007, 2010; Nowell and Davidson 2010).

The increased interest in theory of mind also fed in to research on delusions and irrational or pathological belief-formation, perhaps the area in which Australasian philosophers have most intensively collaborated with cognitive scientists over the last 15 years. The focus has been especially on monothematic delusions like the Capgras delusion (that a familiar person or loved one has been replaced by a stranger or imposter), as well as on schizophrenia, affective disorders, and delusions of agency and control: the emergent discipline of cognitive neuropsychiatry seeks to integrate clinical, neuroscientific, cognitive, and philosophical perspectives on the origin and persistence of such extraordinary and tragic cases (Coltheart and Davies 2000; Hohwy and Rosenberg 2005; Coltheart 2007; Radden 2010). Alongside studies in philosophy of science on the concept of mental disorder and on classification in psychiatry and medicine (Murphy 2006, 2009, 2010), philosophers have contributed centrally to the key theoretical frameworks in the field. Martin Davies, with Max Coltheart and colleagues (2001, 2005; Aimola Davies and Davies 2009) developed a two-factor theory of monothematic delusions, according to which an initial neuropsychological anomaly causes unusual experiences, but is not transformed into a persisting delusion unless joined by a further abnormality in reasoning. Philip Gerrans (2002b) offered an alternative one-factor model of the Cotard delusion (the belief that I am dead). Subsequent debate has addressed the interplay of top-down and bottom-up factors in the genesis and maintenance of delusions (Bayne and Pacherie 2004; Hohwy 2004; Fine, Craigie, and Gold 2005), the link between delusions, selfdeception, and weakness of will (Bayne and Fernandez 2009), questions of rationality and confabulation in schizophrenia and other delusions (Gold and Hohwy 2000; Langdon, Davies, and Coltheart 2002; Coltheart, Menzies, and Sutton 2010; Langdon and Bayne 2010), the role of 
imagination (Currie 2000), and possible neuropsychological mechanisms of delusions (Gerrans 2007, 2009). The attempt to identify specific forms of irrationality that might lie behind the putative second factor (McKay, Langdon, and Coltheart 2007) has also driven broader inquiries into the evolution and mechanisms of misbelief (McKay and Dennett 2009).

\subsection{Other Psychological Processes}

We turn now to specific domains within the philosophy of mind and cognition. In the philosophy of emotion, Paul Redding's The Logic of Affect (1999) critically assesses some cognitive and neurobiological approaches in the course of an analysis of historical theories including those of James and Freud. In a sustained research program, Paul Griffiths has developed an integrated framework for the interdisciplinary study of emotion. Criticizing standard propositional attitude theories of emotion and associated methodological commitments to conceptual analysis, Griffiths instead draws selectively on psychoevolutionary approaches, affect program theory, and social constructionism, arguing that different forms of emotion have distinctive psychological bases. Locating emotion theory firmly within the philosophy of science, and employing naturalistic methods for philosophy of psychology, Griffiths suggests that the category 'emotion' may not bet a natural psychological kind $(1997,2001,2004)$. In particular, he addresses the relation between the 'basic' emotions, which seem to be pancultural, and the complex emotions which play central parts in the larger emotional episodes which matter for moral psychology and personal identity (Griffiths 2003). Identifying pervasive conceptual confusions in debates over the universality of emotions, he revives the Darwinian concept of 'homology' to understand how forms of emotional response can diverge dramatically in distinct contexts even though they share an evolutionary history. This also leads him to develop a thoroughly situated approach to emotion which stresses the way organisms 'probe' their environment through initial emotional responses, so that the dynamic evolution of their emotional states is not the unfolding of an internally-specified genetic blueprint (Griffiths and Scarantino 2009). A dynamical, trajectory-dependent picture of the nature and development of emotion is integrated with personality psychology by Doris Mcllwain, and applied to the genesis of particular personality styles including psychopathy and Machiavellianism (2006, 2007, 2010; see also Langdon and Mackenzie 2011); while Karen Jones examines questions about modularity and the emotions (2007).

Next, we can pick out five strands of philosophical work on imagery, imagination, and perception (see Maund 2003; Stoljar 2009; Fish 2010). Significant interventions in the imagery debate were made by Sterelny $(1986)$ and especially by Slezak $(1990,1995)$, whose conceptual contributions in favour of a tacit knowledge account of images, and against the 'pictorial' theory of mental images, were strengthened by his own psychological experiments to test predictions of the pictorial view (for other work on visual imagery and illusions see Cam 1990b, Candlish 2001). Secondly, work by Currie and others on the philosophy and psychology of imagination made original connections across aesthetics, cognitive science, and philosophy of mind (Currie 1995, Currie and Abell 2000, Currie and Ravenscroft 2002). Thirdly, among the topics significantly advanced by Jackson's Perception: $a$ representative theory (1977), Australasian philosophers took a particular interest in colour perception, a topic which integrated developments in metaphysics and philosophy of mind (Bigelow, Collins, and Pargetter 1990; Maund 1995, 2006; Gold 1999; Menzies 2009). Fourth, questions about the nature of perceptual content have been freshly treated in Schellenberg's account of the essential situation-dependence of perceptual experience, which on her view is both representational and relational (Schellenberg 2008, 2010). Finally, standard issues about direct or naïve realism have continued to be debated since Jackson's staunch defence of the representative theory of perception. In addition to new treatments of representationalism (Maund 1993, 2003) and of naïve realism (Fish $2009,2010)$, an important form of direct realism in the tradition of John Anderson was maintained by theoretical psychologists at the University of Sydney (Mackay and Petocz 2011). Notably, Maze (1983) developed an anti-representationist account of perception and cognition, allied both with a 
sustained attack on the tacit teleology of standard theories of intention and a constructive reinterpretation of Freudian metapsychology; Michell drew out implications of this form of direct realism for issues about both method and measurement in cognitive psychology $(1988,2000)$; and Petocz applied the synthesis of direct realism and psychoanalysis to a general theory of human symbolic activity (1999).

In the philosophy of dreaming, O'Shaughnessy undertook an extraordinarily detailed logicophenomenological inquiry (2002), and Sutton surveyed and pinpointed conceptual difficulties in empirical work (2009). Philosophical work on memory, in turn, continues to reveal the lasting influence of Martin and Deutscher's 'Remembering' (1966). This paper not only set a template for causal theories of mental states in general, and through its notion of 'operative causation' played an important role in the history of the metaphysics of causation: it also modelled an original and striking style of philosophical writing, revisited in Deutscher's later (1989) reflection. Against a broadly Wittgensteinian consensus that remembering was to be analysed simply as the retention of knowledge or of certain abilities, Martin and Deutscher argued that our ordinary concept of remembering in fact includes a requirement of causal continuity between the past event recalled and the present remembering. In turn, they explicated this requirement as involving 'the idea of a memory trace', an enduring state or set of states which to some context-sensitive extent constitutes 'a structural analogue of the thing remembered' (1966, 191; compare Deutscher 1989; Windhorst 2005; Martin 2008; Sutton and Windhorst 2009). Fernandez addressed the content of memory experience (2006a,b, 2008a,b), while Sutton sought to answer criticisms of trace theory, to integrate historical, conceptual, and empirical approaches to remembering (1998a, 2007, 2009), and to assess puzzles about visuospatial perspective in autobiographical memory (2010b). Memory has also emerged as a central topic in moral psychology, where philosophers increasingly draw on ideas from philosophy of psychology in theorizing the temporal dynamics of our individual and collective selfunderstanding (Downham 2005; Jones 2008; Mackenzie 2008; Poole 2008). The cognitive psychological account of autobiographical remembering as 'mental time travel' (Gerrans 2007; Suddendorf and Corballis 2007) has been put to work in research on personality and moral agency (Kennett and Matthews 2009, Mcllwain 2010).

On other topics too, philosophy of mind and cognition has likewise increasingly overlapped to mutual benefit with ethics and moral psychology. Ongoing debates on personal identity, philosophy of action, and moral cognition and moral reasoning are beyond the scope of this chapter, but we can point to some further points of fruitful contact between philosophical traditions and programs. Building on a tradition of investigating implications of empirical psychology and neuroscience for our understanding of agency and the will (Slezak 1986, Price 1989), philosophers have continued to develop theoretical views of the nature of agent control intended to be compatible with the best interpretation of scientific results, in particular arguing against overly dramatic claims that science shows control or the will to be illusory (Levy and Bayne 2004a,b; Bayne 2006, 2011; Ismael 2006, 2007; Pettit 2007; Carruthers 2010: for a different approach to the will see O'Shaughnessy 1980). With the rise of 'neuroethics' (Levy 2007), 'neurolaw' (Vincent 2009), and 'neurosexism' (Fine 2010), we can expect increasing interaction between cognitive philosophy and applied ethics on topics such as addiction, responsibility, and cognitive enhancement.

Some Australasian work in the history of more distant theories of mind has explicitly or critically addressed themes in philosophy of mind and cognition (for example Freeland 1989; Kassler 1995; Gaukroger 1997, 1998; Sutton 1998a, 2000a,b; Macdonald 2003, Brown 2006; Pettit 2009; Thiel 2011). In other work, theoretical approaches to film, literature, art, or technology have been firmly based in specific frameworks from the philosophy of cognition (Currie 1995, 2010; Dutton 2008; Bullot 2009; Boyd 2010; Malpas 2000; Tribble 2011; Tribble and Keene 2011). As philosophers increasingly find points of contact between technical issues in the analysis of mind and cognition and 
problems of wider concern in the sciences, humanities, and in society, the history of Australasian work in philosophy of mind which we have surveyed here offers rich resources. 


\section{References}

Aimola Davies, Anne M. and Martin Davies. 2009. "Explaining Pathologies of Belief", in M. Broome and L. Bortolotti (eds), Psychiatry as Cognitive Neuroscience: philosophical perspectives, pp.285-325. Oxford: Oxford University Press.

Albahari, Miri. 2002. Analytical Buddhism: the two-tiered illusion of self. London: Palgrave Macmillan. Albahari, Miri. 2006. "Against No-Ātman Theories of Anattā". Asian Philosophy 12:5-20.

Albahari, Miri. 2009. "Witness-Consciousness: its definition, appearance, and reality". Journal of Consciousness Studies 16:62-84.

Albury, W.R. and Peter Slezak (eds). 1989. Dimensions of Cognitive Science. Kensington, NSW: UNSW Centre for Cognitive Science.

Amberber, Mengistu (ed). 2007. The Language of Memory in a Cross-Linguistic Perspective. Amsterdam: Elsevier.

Armstrong, D.M. 1991. "Searle's Neo-Cartesian Theory of Consciousness", in Consciousness (Philosophical Issues, 1), edited by E. Villanueva, pp.65-71. Attascadero, California: Ridgeview Publishing Company.

Armstrong, D.M. 1999. The Mind-Body Problem: an opinionated introduction. Boulder, CO: Westview Press.

Atkins, Kim. 2000. "Autonomy and the Subjective Character of Experience". Journal of Applied Philosophy 17:71-79.

Baars, Bernard J. 1988. A Cognitive Theory of Consciousness. Cambridge, Cambridge University Press. Bayne, Timothy J. 2000. "The Unity of Consciousness: clarification and defence". Australasian Journal of Philosophy 78:248-254.

Bayne, Timothy J. 2004. "Closing the Gap: some questions for neurophenomenology".

Phenomenology and the Cognitive Sciences 3:349-64.

Bayne, Timothy J. 2006. "Phenomenology and the Feeling of Doing: Wegner on the Conscious Will", in S. Pockett, W. P. Banks and S. Gallagher (eds.) Does Consciousness Cause Behavior?, pp. 169-186. Cambridge, MA: MIT Press.

Bayne, Timothy J. 2007. "Conscious States and Conscious Creatures: explanation in the scientific study of consciousness". Philosophical Perspectives 21:1-22.

Bayne, Timothy J. 2008. "The Unity of Consciousness and the Split-Brain Syndrome". Journal of Philosophy 105: 277-300.

Bayne, Timothy J. 2009. "The Sense of Agency", in The Senses, edited by Fiona Macpherson. Oxford, Oxford University Press.

Bayne, Tim. 2010. The Unity of Consciousness. Oxford: Oxford University Press.

Bayne, Tim and David Chalmers. 2003. "What Is the Unity of Consciousness?", in The Unity of

Consciousness, edited by A. Cleeremans, pp.23-58. Oxford: Oxford University Press.

Bayne, Tim, Axel Cleeremans, and Patrick Wilken (eds). 2009. The Oxford Companion to

Consciousness. Oxford: Oxford University Press.

Bayne, Timothy J. and Neil Levy. 2006. "The Feeling of Doing: deconstructing the phenomenology of agency", in Disorders of Volition, edited by N. Sebanz and W. Prinz. Cambridge, MA: MIT Press.

Bayne, Timothy J. and Elisabeth Pacherie. 2007. "Narrators and Comparators: the architecture of agentive self-awareness". Synthese 159:475-491.

Bayne, Timothy J. 2011. "Libet and the Case for Free Will Scepticism", in R. Swinburne (ed) Free Will and Modern Science. Oxford: Oxford University Press.

Bayne, Tim and Jordi Fernandez (eds.). 2009. Delusion and Self-Deception: affective and motivational influences on belief formation. Brighton: Psychology Press.

Bayne, Timothy J. and Neil Levy. 2005. Amputees by Choice: Body Integrity Identity Disorder and the Ethics of Amputation. Journal of Applied Philosophy 22 (1):75-86.

Bayne, Timothy J. and Neil Levy. 2006. "The Feeling of Doing: deconstructing the phenomenology of agency", in N. Sebanz and W. Prinz (eds) Disorders of Volition pp. 49-68. Cambridge, MA: MIT Press. 
Bayne, Timothy J. and Elisabeth Pacherie. 2004. "Bottom-up or Top-down? Campbell's rationalist account of monothematic delusions". Philosophy, Psychiatry, and Psychology, 11:1-11.

Bechtel, William, George Graham, and Adele Abrahamsen. 1998. "The Life of Cognitive Science", in W. Bechtel and G. Graham (eds), A Companion to Cognitive Science, pp.2-53. Oxford: Blackwell. Bigelow, John, John Collins, and Robert Pargetter. 1990. "Colouring in the World". Mind 99:279-288. Bigelow, John and Robert Pargetter. 1990. "Acquaintance with Qualia". Theoria 56: 129-147. Bigelow, John and Robert Pargetter. 2006. "Re-Acquaintance with Qualia". Australasian Journal of Philosophy 84: 353-378.

Bliss, Suzanne and Jordi Fernandez. 2010. "Program Explanation and Higher-Order Properties". Acta Analytica 25:393-411.

Block, Ned. 2007. “Consciousness, Accessibility, and the Mesh between Psychology and Neuroscience". Behavioral and Brain Sciences 30: 481-548.

Boden, Margaret A. 2006. Mind as Machine: a history of cognitive science. 2 vols, Oxford: Oxford University Press.

Boyd, Brian. 2010. On the Origin of Stories: evolution, cognition, and fiction. Cambridge, MA: Harvard University Press.

Braddon-Mitchell, David. 2003. "Qualia and Analytical Conditionals". Journal of Philosophy 100:111135.

Braddon-Mitchell, David and John Fitzpatrick. 1990. "Explanation and the Language of Thought". Synthese 83:3-29.

Braddon-Mitchell, David and Frank C. Jackson. 1997. "The Teleological Theory of Content". Australasian Journal of Philosophy 75:474-489.

Braddon-Mitchell, David and Frank C. Jackson. (2006). Philosophy of Mind and Cognition: an introduction, $2^{\text {nd }}$ edition. Oxford: Wiley-Blackwell.

Brooks, Rodney A. 1990. "Elephants Don't Play Chess". Robotics and Autonomous Systems 6:3-15, reprinted in Brooks, Cambrian Intelligence. Cambridge, MA: MIT Press, 1999.

Brooks, Rodney A. 1991. "Intelligence without Representation". Artificial Intelligence 47:139-159, reprinted in Brooks, Cambrian Intelligence. Cambridge, MA: MIT Press, 1999.

Brooks, Rodney A. 1992. "Artificial Life and Real Robots". In F.J. Varela and P. Bourgine (eds), Toward a Practice of Autonomous Systems, pp.3-10. Cambridge, MA: MIT Press.

Brooks, Cambrian Intelligence - cite the early papers

2006 Descartes and the passionate mind (Cambridge: Cambridge University Press).

Brown, Deborah J. 1993 "Swampman of La Mancha". Canadian Journal of Philosophy 23:327-348.

Brown, Deborah J. 2006. Descartes and the Passionate Mind. Cambridge: Cambridge University

Press.

Browne, Derek. 2004. "Do Dolphins Know Their Own Minds?". Biology and Philosophy 19:633-653. Bullot, Nicolas J. 2009. "Material Anamnesis and the Prompting of Aesthetic Worlds: the psychohistorical theory of artworks". Journal of Consciousness Studies 16:85-109.

Cam, Philip. 1984. "Dennett on Intelligent Storage". Philosophy and Phenomenological Research 45:247-61.

Cam, Philip. 1988. "Modularity, Rationality, and Higher Cognition". Philosophical Studies. 53:279294.

Cam, Philip. 1989. "Notes Toward a Faculty Theory of Consciousness", in P. Slezak and R. Albury (eds), Computers, Brains and Minds, pp.167-191. Dordrecht: Kluwer.

Cam, Philip. 1990a. "Searle on Strong Al". Australasian Journal of Philosophy 68:103-8.

Cam, Philip. 1990b. "Insularity and the Persistence of Perceptual Illusions". Analysis 50:231-5.

Campbell, Keith. 1986. "Can Intuitive Psychology Survive the Growth of Neuroscience?". Inquiry 29:143-152.

Campbell, Keith. 1993. "What Motivates Eliminativism?" Mind and Language 8:206-210.

Candlish, M.S. 1996. "Wittgenstein and the Doctrine of Kinaesthesis". Australasian Journal of

Philosophy 74:581-597. 
Candlish, M.S. 2001. "Mental Imagery", in Wittgenstein and Contemporary Philosophy of Mind. Palgrave Macmillan.

Carruthers, Glenn 2008. "Types of Body Representation and the Sense of Embodiment". Consciousness and Cognition 17: 1302-1316.

Carruthers, Glenn 2009. "Is the Body Schema Sufficient for the Sense of Embodiment? An alternative to de Vignemont's model". Philosophical Psychology 22:123-142.

Carruthers, Glenn. 2010. "A Problem for Wegner and Colleagues' Model of the Sense of Agency". Phenomenology and the Cognitive Sciences 9:341-357.

Carruthers, Glenn. 2011. "The Case for the Comparator Model as an explanation of the sense of agency and its breakdowns". Consciousness and Cognition.

Chadha, Monima. 2007. "No Speech, Never Mind!". Philosophical Psychology 20:641-657.

Chadha, Monima. 2011. "Self-Awareness: eliminating the myth of the 'invisible subject". Philosophy

East and West 61:453-467.

Chalmers, David J. 1990. "Syntactic Transformations on Distributed Representations". Connection

Science 2:53-62.

Chalmers, David J.1992. "Subsymbolic Computation and the Chinese Room", in J. Dinsmore ( ed) The

Symbolic and Connectionist Paradigms: closing the gap, pp.25-48. Hillsdale, NJ: Lawrence Erlbaum.

Chalmers, David, J. 1995. "The Puzzle of Conscious Experience." Scientific American 237(6): 62-68.

Chalmers, David J. 1996a. The Conscious Mind: In Search of a Fundamental Theory. Oxford: Oxford University Press.

Chalmers, David J. 1996b. "Does a Rock Implement Every Finite-State Automaton?" Synthese 108: 310-333.

Chalmers, David J. 1998."On the Search for the Neural Correlate of Consciousness", in Toward a Science of Consciousness li: The Second Tucson Discussions and Debates, edited by S. Hameroff, A. Kaszniak and A. Scott. Cambridge, MA: MIT Press.

Chalmers, David J. 2000. "What Is a Neural Correlate of Consciousness?", in Neural Correlates of Consciousness: Empirical and Conceptual Issues, edited by T. Metzinger. Cambridge MA: MIT Press. Chalmers, David J. 2004. "How Can We Construct a Science of Consciousness?", in The Cognitive Neurosciences, edited by M. Gazzaniga. Cambridge, MA: MIT Press.

Chalmers, David J. 2009. "The Two-Dimensional Argument Against Materialism", in B. McLaughlin (ed.), The Oxford Handbook of Philosophy of Mind, pp. 313-335. Oxford: Oxford University Press. Chalmers, David J. 2010. The Character of Consciousness. Oxford: Oxford University Press. Chalmers, David J. 2012. "A Computational Foundation for the Study of Cognition". Journal of Cognitive Science (partly published as "On Implementing a Computation", Minds and Machines 4:391-402, 1994).

Christensen, Wayne D. 2007. "The Evolutionary Origins of Volition". In Distributed Cognition and the Will: individual volition and social context, edited by Don Ross, David Spurrett, Harold Kincaid, and G. Lynn Stephens, 255-287. Cambridge, MA: MIT Press.

Christensen, Wayne D. 2010. "The Decoupled Representation Theory of the Evolution of Cognition: a critical reassessment". British Journal for the Philosophy of Science 61:361-405.

Christensen, Wayne D. and Mark H. Bickhard. 2002 "The Process Dynamics of Normative Function". Monist 85:3-28.

Christensen, Wayne D. and Cliff A. Hooker. 2002. "Self-Directed Agents", in J.J. Maclntosh (ed.), Naturalism, Evolution, and Intentionality (Canadian Journal of Philosophy, Supplementary Volume XXVII), pp. 19-52. Calgary: University of Calgary Press.

Christensen, Wayne D. and Cliff A. Hooker. 2004. "Representation and the Meaning of Life", in Representation in Mind: new approaches to mental representation, edited by Hugh Clapin, pp.41-69. Amsterdam: Elsevier.

Churchland, Paul M. 1989. A Neurocomputational Perspective. Cambridge, MA: MIT Press.

Churchland, Paul M. 2005. "Chimerical Colour: some phenomenological predictions from cognitive neuroscience". Philosophical Psychology 18:527-560. 
Clapin, Hugh. 1995. "Which Symbols have 'Meaning for the Machine'?". In Perspecties on Cognitive Science: theories, experiments, and foundations, edited by Peter Slezak, Terry Caelli, and Richard Clark, 317-329. Norwood, NJ: Ablex.

Clapin, Hugh (ed). 2002. Philosophy of Mental Representation. Oxford: Oxford University Press. Clark, Andy. 1997. Being There: putting brain, body, and world together again. Cambridge, MA: MIT Press.

Clark, Andy. 2003. Natural-Born Cyborgs. Oxford: Oxford University Press.

Clark, Andy and David J. Chalmers. 1998. "The Extended Mind". Analysis 58:7-19.

Cleland, Kathy. 2010. "Mixed Reality Interaction: audience responses to robots and virtual characters". Digital Creativity 21:30-38.

Coltheart, Max. 1999. "Modularity and Cognition". Trends in Cognitive Sciences 3:115-120.

Coltheart, Max. 2006a. "What has Functional Neuroimaging Told Us About the Mind (so far)?". Cortex 42:323-331.

Coltheart, Max. 2006b. "Perhaps Functional Neuroimaging Has Not Told Us Anything About the Mind (So Far)". Cortex 42:422-427.

Coltheart, Max. 2007. "Cognitive Neuropsychiatry and Delusional Belief". Quarterly Journal of Experimental Psychology 60:1041-1062.

Coltheart, Max. 2010. "Levels of Explanation in Cognitive Science". ASCS09: Proceedings of the 9th Conference of the Australasian Society for Cognitive Science, edited by W.D. Christensen, E. Schier and J. Sutton. Sydney: Macquarie Centre for Cognitive Science.

Coltheart, Max and Martin Davies. 2000. Pathologies of Belief. Oxford: Blackwell.

Coltheart, Max and Robyn Langdon. 1998. "Autism, Modularity and Levels of Explanation in

Cognitive Science". Mind and Language 13:138-152.

Coltheart, Max, Peter Menzies, and John Sutton. 2010. "Abductive Inference and Delusional Belief". Cognitive Neuropsychiatry 15:261-287.

Copeland, B. Jack. 1993. Artificial Intelligence: a philosophical introduction. Oxford: Blackwell.

Copeland, B. Jack. 1996. "What is Computation?". Synthese 108:335-359.

Copeland, B. Jack. 1997. "The Church-Turing Thesis". Stanford Encyclopedia of Philosophy. URL: http://plato.stanford.edu/entries/church-turing/.

Copeland, B. Jack. 2000a. "Narrow versus Wide Mechanism: including a re-examination of Turing's views on the mind-machine issue". Journal of Philosophy 97:5-32.

Copeland, B. Jack. 2000b. "The Turing Test". Minds and Machines 10:519-539.

Copeland, B. Jack. 2002. "The Chinese Room from a Logical Point of View". In Views into the Chinese Room: new essays on Searle and artificial intelligence, edited by J. Preston and M. Bishop, 109-122.

Oxford: Clarendon Press.

Copeland, B. Jack (ed). 2004. The Essential Turing. Oxford: Oxford University Press.

Copeland, B. Jack (ed). 2005. Alan Turing's Automatic Computing Engine. Oxford: Oxford University Press.

Copeland, B. Jack, and Diane Proudfoot. 1996. "On Alan Turing's Anticipation of Connectionism". Synthese 108:361-377.

Copeland, B. Jack, and Richard Sylvan. 1999. Beyond the Universal Turing Machine. Australasian Journal of Philosophy 77:46-66.

Coutts, Tama. 2008. "Playing Chess in the Chinese Room", in B. Hale (ed), Philosophy Looks at Chess, pp.25-38. Chicago, IL: Open Court.

Cowie, Fiona. 1998. What's Within? Nativism Reconsidered. Oxford: Oxford University Press.

Currie, Greg. 1995. Image and Mind: film, philosophy and cognitive science. Cambridge: Cambridge University Press.

Currie, Greg. 2000. Imagination, Delusion and Hallucinations. Mind and Language 15:168-183.

Currie, Greg. 2010. Narratives and Narrators: a philosophy of stories. Oxford: Oxford University Press. 
Currie, Greg and Catharine Abell. 2000. Internal and External Pictures. Philosophical Psychology 12: 429-445.

Currie, Greg and lan Ravenscroft. 2002. Recreative Minds: Imagination in Philosophy and Psychology. Oxford: Oxford University Press.

Currie, Greg and Kim Sterelny. 2000. "How to Think about the Modularity of Mindreading".

Philosophical Quarterly 50:145-160.

Dartnall, Terry. 2007. "Internalism, Active Externalism, and Nonconceptual Content: the ins and outs of cognition". Cognitive Science 31:257-283.

Davids, Keith, Chris Button, and Simon Bennett. 2007. Dynamics of Skill Acquisition: a constraints-led approach. Human Kinetics.

Davidson, lain. 2007. "'As large as you need and as small as you can': implications of the brain size of Homo floresiensis", in A. Schalley and D. Khlentzos (eds), Mental States: evolution, function, nature, pp.35-42. Amsterdam: John Benjamins.

Davidson, lain. 2010. "The Archaeology of Cognitive Evolution". Wiley Interdisciplinary Reviews in Cognitive Science 1:214-229.

Davies, Martin. 1989. "Connectionism, Modularity, and Tacit Knowledge". British Journal for the Philosophy of Science 40:541-55.

Davies, Martin, Max Coltheart, Robyn Langdon, and Nora Breen. 2001. "Monothematic Delusions: towards a two-factor account". Philosophy, Psychiatry, and Psychology 8:133-158.

Davies, Martin, Anne Aimola Davies, and Max Coltheart. 2005. "Anosognosia and the Two-Factor Theory of Delusions". Mind and Language 20:241-57.

Davies, Martin and Tony Stone (eds). 1995a. Folk Psychology: the theory of mind debate. Oxford: Blackwell.

Davies, Martin and Tony Stone (eds). 1995b. Mental Simulation. Oxford: Blackwell.

de Zubicaray, Greig I.2006. "Cognitive Neuroimaging: cognitive science out of the armchair". Brain and Cognition 60:272-281.

Deutscher, Max. 1989. "Remembering 'Remembering'”, in J. Heil (ed), Cause, Mind, and Reality, pp.53-72. Dordrecht: Kluwer.

Deutscher, Max. 2010. "Philosophy of Mind (Continental)". In A Companion to Philosophy in Australia \& New Zealand, edited by Graham Oppy and N.N. Trakakis, pp.419-424, Clayton, Vic: Monash University Press.

Devitt, Michael. 1989. "A Narrow Representational Theory of the Mind", in S. Silvers (ed), Rerepresentation: readings in the philosophy of mental representation, pp.369-402. Dordrecht: Kluwer.

Devitt, Michael. 1996. Realism and Truth. $2^{\text {nd }}$ edition, Princeton NJ: Princeton University Press. Devitt, Michael. 2011. "Methodology and the Nature of Knowing How". Journal of Philosophy.

Diprose, Rosalyn and Robyn Ferrell (eds). 1991. Cartographies: poststructuralism and the mapping of bodies and spaces. Allen and Unwin.

Doggett, Tyler and Daniel Stoljar. 2010. “Does Nagel's Footnote 11 Solve the Mind-Body Problem?". Philosophical Issues 20:125-143.

Downey, Greg. 2005. Learning Capoeira: lessons in cunning from an Afro-Brazilian art. Oxford:

Oxford University Press.

Downey, Greg. 2010a. "Practice without Theory: a neuroanthropological perspective on embodied learning". JRAl: Journal of the Royal Anthropological Institute 16:S22-S40.

Downey, Greg. 2010b. "Throwing Like a Brazilian: on ineptness and a skill-shaped body", in R. Sands (ed), Anthropology of Sport and Human Movement, pp. 297-326. Lanham, MD: Rowman \& Littlefield. Downham, Russell. 2005. "Seeking Self-Consistency with Integrity: an interdisciplinary approach to the ethics of self and memory". Scan. URL:

http://scan.net.au/scan/journal/display.php?journal id=57

Drayson, Zoe. 2010. "Extended Cognition and the Metaphysics of Mind". Cognitive Systems Research 11:367-377. 
Dutton, Denis. 2008. The Art Instinct: beauty, pleasure, and human evolution. Bloomsbury. Fernandez, Jordi. 2006a. "The Intentionality of Memory". Australasian Journal of Philosophy 84:3957.

Fernandez, Jordi. 2006b. "Memory and Perception: remembering Snowflake". Theoria 56:147-164. Fernandez, Jordi. 2008a. "Memory, Past, and Self". Synthese 160:103-121.

Fernandez, Jordi. 2008b. "Memory and Time". Philosophical Studies 141:333-356.

Ferrell, Robyn. 1992. Passion in Theory. London: Routledge.

Files, Craig. 1996. "Goodman's Rejection of Resemblance". British Journal of Aesthetics 36:398-412.

Fine, Cordelia. 2010. Delusions of Gender: how our minds, society, and neurosexism create

difference. New York: W.W. Norton.

Fine, Cordelia, Craigie, Jill, \& Gold, lan. (2005). Damned if you do; Damned if you don't: The impasse in cognitive accounts of the Capgras delusion. Philosophy, Psychiatry, \& Psychology 12:143-151.

2010).

Fish, William. 2009. Perception, Hallucination, and Illusion. Oxford: Oxford University Press.

Fish, William. 2010. Philosophy of Perception: a contemporary introduction. London: Routledge.

Fodor, Jerry A. 1975. The Language of Thought. New York: Thomas Crowell.

Fodor, Jerry A. 1987. Psychosemantics: the problem of meaning in the philosophy of mind.

Cambridge, MA: MIT Press.

Forrest, Peter. 2010. "Materialism, Australian", in G. Oppy and N. Trakakis (eds), A Companion to

Philosophy in Australia and New Zealand, pp.269-271. Clayton, Vic: Monash University Press.

Foss, Jeffrey. 1992. Introduction to the Epistemology of the Brain: indeterminacy, micro-specificity, chaos, and openness. Topoi 11:45-57.

Franklin, James. 2003. Corrupting the Youth: a history of philosophy in Australia. Sydney: Macleay Press.

Freeland, Guy. 1989. "In Quest of a Cognitive Historiography", in W.R. Albury and P. Slezak (eds), Dimensions of Cognitive Science, pp.1-19. Kensington, NSW: University of NSW Press.

Frith, Christopher 1992. The Cognitive Neuropsychology of Schizophrenia. Hillsdale, NJ: Lawrence Erlbaum.

Garfield Jay L. 1997. "Mentalese Not Spoken Here: computation, cognition and causation."

Philosophical Psychology 10:413-435.

Garfield, Jay L, Candida C. Peterson, and Tricia Perry. 2001. "Social Cognition, Language Acquisition and the Development of the Theory of Mind. Mind and Language 16:494-541.

Gatens, Moira. 1995. Imaginary Bodies: ethics, power, and corporeality. London: Routledge.

Gaukroger, Stephen. 1997. "Nature without Reason: Cartesian automata and perceptual cognition". In Gaukroger, The Genealogy of Knowledge. Aldershot: Ashgate.

Gaukroger, Stephen (ed). 1998. The Soft Underbelly of Reason: the passions in the seventeenth century. London: Routledge.

Gerrans, Philip. 1998. "The Norms of Cognitive Development". Mind and Language 13:56-75.

Gerrans, Philip. 2001. "Delusions as Performance Failures". Cognitive Neuropsychiatry 31, 161-173.

Gerrans, Philip. 2002a. "The Theory of Mind Module in Evolutionary Psychology." Biology and

Philosophy 17:305-321.

Gerrans, Philip. 2002b. "A One-Stage Explanation of the Cotard Delusion”. Philosophy, Psychiatry, and Psychology 9:47-53.

Gerrans, Philip. 2003. "Nativism and Neuroconstructivism in the Explanation of Williams Syndrome". Biology and Philosophy 18:41-52.

Gerrans, Philip. 2005. "Wittgenstein and Bourdieu on Tacit Knowledge". Anthropological Theory 15:53-74.

Gerrans, Philip. 2007a. "Mechanisms of Madness: evolutionary psychiatry without evolutionary psychology". Biology and Philosophy 22:35-56.

Gerrans, Philip. 2007b. "Mental Time Travel, Somatic Markers and 'Myopia for the Future'”. Synthese 159:459-474. 
Gerrans, Philip. 2009. "Mad Scientists or Unreliable Autobiographers: dopamine dysregulation and delusion", in M. Broome and L. Bortolotti (eds), Psychiatry as Cognitive Neuroscience: philosophical perspectives, pp.151-171. Oxford: Oxford University Press.

Gerrans, Philip and Valerie E. Stone. 2008. "Generous or Parsimonious Cognitive Architecture? Cognitive Neuroscience and Theory of Mind". British Journal for the Philosophy of Science 59:121141.

Gerrans, Philip and Jeanette Kennett. 2010. "Neurosentimentalism and Moral Agency". Mind 119:585-614.

Godfrey-Smith, Peter. 1989. “Misinformation” Canadian Journal of Philosophy 19:533-550.

Godfrey-Smith, Peter. 1992. "Indication and Adaptation". Synthese 92:283-312.

Godfrey-Smith, Peter. 1996.Complexity and the Function of Mind in Nature. Cambridge: Cambridge University Press

Godfrey-Smith, Peter. 2002."On the Evolution of Representational and Interpretive Capacities". Monist 85:50-69.

Godfrey-Smith, Peter. 2004."On Folk Psychology and Mental Representation", in H. Clapin, P. Staines, and P. Slezak (eds.) Representation in Mind: New Approaches to Mental Representation. Amsterdam: Elsevier, 147-162.

Godfrey-Smith, Peter. 2005. "Folk Psychology as a Model". The Philosopher's Imprint 5: 1-16. Godfrey-Smith, Peter. 2006. "Mental Representation, Naturalism, and Teleosemantics", in Graham Macdonald and David Papineau (eds), Teleosemantics: New Philosophical Essays,_42-68. Oxford: Oxford University Press.

Gold, Ian. 1999. "Dispositions and the Central Problem of Color". Philosophical Studies 93 (1):21-44. Gold, Ian. 2004. "Phenomenal Qualities and Intermodal Perception", in Representation in Mind: new approaches to mental representation, edited by Hugh Clapin, 125-146. Amsterdam: Elsevier. Gold, Ian. 2010. "Philosophical Psychology" , in G. Oppy and N. Trakakis (eds), A Companion to Philosophy in Australia and New Zealand, pp.369-370. Clayton, Vic: Monash University Press. Gold, Ian and Hohwy, Jakob. 2000. "Rationality and Schizophrenic Delusion". Mind and Language 15:146-167.

Gold, Ian and Daniel Stoljar. 1999. "A Neuron Doctrine in the Philosophy of Neuroscience". Behavioral and Brain Sciences 22:809-830.

Griffiths, Paul E. 1997. What Emotions Really Are: the problem of psychological categories. Chicago: University of Chicago Press.

Griffiths, Paul E. 2001. Emotion and the problem of psychological categories. Emotions, Qualia and Consciousness A.W. Kazniak (Ed). Singapore, New Jersey, Hong Kong, London, World Scientific 28-41. Griffiths, Paul E. 2002. "What is Innateness?". Monist, 85:70-85.

Griffiths, Paul E. 2003. "Basic Emotions, Complex Emotions, Machiavellian Emotions", in Philosophy and the Emotions, A. Hatzimoysis (Ed.), pp. 39-67. Cambridge, Cambridge University Press.

Griffiths, Paul E. 2004. "Is Emotion a Natural Kind?", in Philosophers on Emotion, R. C. Solomon (ed.), pp. 233-249. Oxford: Oxford University Press.

Griffiths, Paul E. 2007. "Evo-Devo Meets the Mind: towards a developmental evolutionary psychology", in Integrating Development and Evolution, R. Sanson \& R.N. Brandon (eds.), pp. 195225. Cambridge: Cambridge University Press.

Griffiths, Paul E. and Edouard Machery. 2008. "Innateness, Canalization, and 'Biologicizing the Mind'”. Philosophical Psychology 21:397-414.

Griffiths, Paul E. and Andrea Scarantino. 2009.."Emotions in the Wild: the situated perspective on emotion", in P. Robbins and M. Aydede (eds.) Cambridge Handbook of Situated Cognition, Cambridge: Cambridge University Press, 437-453.

Griffiths, Paul E. and Karola Stotz. 2000. "How the Mind Grows: a developmental perspective on the biology of cognition". Synthese 122:29-51.

Grove, Robin, Catherine Stevens, and Shirley McKechnie (eds). 2005. Thinking in Four Dimensions. Melbourne: Melbourne University Press. 
Hohwy, Jakob. 2004. "Top-down and Bottom-up in Delusion Formation". Philosophy, Psychiatry and Psychology 11: 65-70.

Hohwy, Jakob. 2007. "The Sense of Self in the Phenomenology of Agency and Perception". Psyche 13.

Hohwy, Jakob.2009. "The Neural Correlates of Consciousness: new experimental approaches needed?". Consciousness and Cognition 18:428-438.

Hohwy, Jakob. 2010). "The Hypothesis-Testing Brain: some philosophical implications". In ASCS09: Proceedings of the 9th Conference of the Australasian Society for Cognitive Science. Edited by Wayne Christensen, Elizabeth Schier, and John Sutton. Sydney: Macquarie Centre for Cognitive Science. Hohwy, Jakob and Christopher Frith. 2004. "Can Neuroscience Explain Consciousness?". Journal of Consciousness Studies 11:180-198.

Hohwy, Jakob and J. Kallestrup (eds). 2008. Being Reduced: New Essays on Reduction, Explanation, and Causation. Oxford: Oxford University Press.

Hohwy, Jakob and Bryan Paton. 2010. "Explaining Away the Body: experiences of supernaturally caused touch and touch on non-hand objects within the rubber hand illusion". PLoS ONE 5: e9416. http://dx.plos.org/10.1371/journal.pone.0009416

Hohwy, Jakob and Raben Rosenberg. 2005. "Cognitive Neuropsychiatry: conceptual, methodological and philosophical perspectives". The World Journal of Biological Psychiatry 6:192-197.

Hooker, C. A. 1981. "Towards a General Theory of Reduction. Part II: identity in reduction". Dialogue 20:201-236.

Hooker, C. A. 2004. "Asymptotics, Reduction and Emergence". British Journal for the Philosophy of Science 55:435-479.

Hooker, C. A. 2006. "Reduction as Cognitive Strategy", in Paul Churchland, pp.154-174. Cambridge: Cambridge University Press.

Hooker, C.A. 1998. "Being There: putting philosopher, researcher, and student together again". Symposium on Clark 1997. Metascience 7:70-77.

Hooker, C.A. and W.D. Christensen. 1998. "Towards a New Science of the Mind: wide content and the metaphysics of organizational properties in non-linear dynamical models'. Mind \& Language 13:98-109.

Hooker, C.A., H.B. Penfold, and R.J. Evans. 1992. "Control, Connectionism, and Cognition: towards a new regulatory paradigm". British Journal for the Philosophy of Science 43:517-536.

Hurley, Susan. 1998. Consciousness in Action. Cambridge, MA: Harvard University Press.

Hutchins, Edwin. 1995. Cognition in the Wild. Cambridge, MA: MIT Press.

Hyslop, Alec. 1995. Other Minds. Dordrecht: Kluwer.

Hyslop, Alec. 2005. "Other Minds". Stanford Encyclopedia of Philosophy. URL:

http://plato.stanford.edu/entries/other-minds/.

Ismael, Jenann. 2006. "Saving the Baby: Dennett on autobiography, agency, and the self".

Philosophical Psychology 19:345-360.

Ismael, Jenann. 2007. The Situated Self. Oxford: Oxford University Press.

Jackson, Frank C. 1977. Perception: a representative theory. Cambridge: Cambridge University Press.

Jackson, Frank C. 1982. "Epiphenomenal Qualia”. Philosophical Quarterly 32:127-136.

Jackson, Frank C. 1986. "What Mary Didn't Know". Journal of Philosophy 83:291-295.

Jackson, Frank C. 1996. "Mental Causation". Mind 105:377-413.

Jackson, Frank C. 1998. Mind, Method, and Conditionals : Selected Essays. London: Routledge.

Jackson, Frank C. 1999. "All that can be at issue in the Theory-Theory/ Simulation Debate".

Philosophical Papers 28:77-96.

Jackson, Frank C. 2004a. "Mind and Illusion", in There's Something About Mary: essays on phenomenal consciousness and Frank Jackson's Knowledge Argument, edited by P. Ludlow, Y. Nagasawa and D. Stoljar. Cambridge, MA: MIT Press.

Jackson, Frank C. 2004b. "Representation and Experience", in Representation in Mind: new approaches to mental representation, edited by Hugh Clapin. Amsterdam: Elsevier. 
Jackson, Frank C. 2009. "Replies to My Critics", in Minds, Ethics and Conditionals: themes from the philosophy of Frank Jackson, edited by I. Ravenscroft. Oxford: Clarendon Press.

Jackson, Frank C. and Philip Pettit. 1988. "Functionalism and Broad Content". Mind 97:381-400. Jackson, Frank C. and Philip Pettit. 1990a. "Causation in the Philosophy of Mind" Philosophy and Phenomenological Research 50:195-214.

Jackson, Frank C. and Philip Pettit. 1990b."Program Explanation: a general perspective" Analysis 50:107-117.

Jackson, Frank C. and Philip Pettit. 1990c. "In Defence of Folk Psychology". Philosophical Studies 57:7-30.

Jackson, Frank C. and Philip Pettit. 1993. "Some Content is Narrow". in J. Heil and A. Mele (eds), Mental Causation, pp. 259-282. Oxford: Oxford University Press.

Jeffares, Ben. 2010. "The Co-evolution of Tools and Minds: cognition and material culture in the hominin lineage". Phenomenology and the Cognitive Sciences 9:503-520.

Jones, Karen. 2007. "Quick and Smart: modularity and the pro-emotion consensus." The Canadian Journal of Philosophy Supp. 2007.

Jones, Karen. 2008. "How to Change the Past.", in C. Mackenzie and K. Atkins (eds) Practical Identity and Narrative Agency, pp.269-288. London: Routledge.

Kassler, Jamie C. 1995. Inner Music: Hobbes, Hooke, and North on internal character. London:

Athlone Press.

Kennett, Jeanette and Steve Matthews. 2009. "Mental Time Travel, Agency, and Responsibility", in M. Broome and L. Bortolotti (eds), Psychiatry as Cognitive Neuroscience: philosophical perspectives, pp.327-350. Oxford: Oxford University Press.

Kim, Jaegwon 1998. Mind in a Physical World: an essay on the mind-body problem and mental causation. Cambridge, MA: MIT Press.

Koksvik, Ole. 2010. "Consciousness, Metaphysics of" , in G. Oppy and N. Trakakis (eds), A Companion to Philosophy in Australia and New Zealand, pp.127-134. Clayton, Vic: Monash University Press.

Korb, Kevin B. (1998). "The Frame Problem: an Al fairy tale". Minds and Machines 8:317-351.

Langdon, Robyn and Timothy J. Bayne. 2010. "Delusion and Confabulation: mistakes of seeing, remembering, and believing". Cognitive Neuropsychiatry 15: 319-45.

Langdon, Robyn, Martin Davies, and Max Coltheart. 2002. "Understanding Minds and Understanding Communicated Meanings in Schizophrenia". Mind and Language 17:68-104.

Langdon, Robyn and Catriona Mackenzie (eds). 2011. Emotions, Imagination, and Moral Reasoning. London: Psychology Press.

Levy, I., C. Trevarthen, et al. 1972. "Perception of Bilateral Chimeric Figures Following Hemispheric Deconnexion". Brain 95:61-78.

Levy, Neil. 2007. Neuroethics. Cambridge: Cambridge University Press.

Levy, Neil. 2008. "Does Phenomenology Overflow Access?". Journal of Consciousness Studies 15:2938.

Levy, Neil and Tim Bayne. 2004a. "A Will of One's Own: consciousness, control and character" International Journal of Law and Psychiatry 27: 459-70.

Levy, Neil and Tim Bayne. 2004b. "Doing Without Deliberation: automatism, automaticity, and moral accountability". International Review Of Psychiatry 16:209-215.

Lewis, David. 1990. What Experience Teaches. Proceedings of the Russellian Society 13:29-57.

Lloyd, Genevieve (1984). The Man of Reason: 'male' and 'female' in Western philosophy. London:

Routledge.

Lycan, William G. 2010. "Functionalism" , in G. Oppy and N. Trakakis (eds), A Companion to Philosophy in Australia and New Zealand, pp.196-202. Clayton, Vic: Monash University Press. Lyon, Pamela. 2004. "Autopoesis and Knowing: reflections on Maturana's biogenic explanation of cognition". Cybernetics and Human Knowing 11:21-46.

Lyon, Pamela. 2006. "The Biogenic Approach to Cognition". Cognitive Processing7:11-29.

Macdonald, Cynthia. 2004. "Mary Meets Molyneux". Nous 38:503-524. 
Macdonald, Cynthia and Graham MacDonald. 1995. "How to Be Psychologically Relevant", in Philosophy of Psychology: Debates on Psychological Explanation, Volume One, edited by C. Macdonald and G. MacDonald, pp. 60-77. Oxford: Blackwell.

Macdonald, Cynthia and Graham MacDonald. 2006. "The Metaphysics of Mental Causation". Journal of Philosophy 103:539-576.

Macdonald, Cynthia and Graham MacDonald. 2007. "Beyond Program Explanation", in Common Minds: Essays in Honour of Philip Pettit, edited by G. Brennan, R. Goodin and M. Smith, pp.1-27. Oxford, Oxford University Press.

Macdonald, Paul. 2003. History of the Concept of Mind. Aldershot: Ashgate.

Mcllwain, Doris J.F. 2006. "Already Filtered: affective immersion and personality differences in accessing present and past". Philosophical Psychology 19:381-399.

Mcllwain, Doris J.F. 2007. "Rezoning Pleasure: drives and affects in personality theory". Theory and Psychology 17:529-561.

Mcllwain, Doris J.F. 2010. "Living Strangely in Time: emotions, masks and morals in psychopathicallyinclined people". European Journal of Analytic Philosophy 6:75-94.

Mackay, Nigel and Agnes Petocz (eds). 2011. Realism and Psychology: collected essays. Leiden: E.J. Brill.

McKay, Ryan and Daniel C. Dennett. 2009. "The Evolution of Misbelief". Behavioral and Brain Sciences 32:493-561.

McKay, Ryan, Langdon, Robyn, and Coltheart, Max. 2007. "Jumping to Delusions? Paranoia, probabilistic reasoning and need for closure". Cognitive Neuropsychiatry, 12:362-376.

Mackenzie, Adrian. 2004. "We Have Always Been ... Cyborgs. Symposium on Clark 2003". Metascience 13:153-163.

Mackenzie, Catriona. 2008. "Imagination, Identity, and Self-Transformation", in C. Mackenzie and K. Atkins (eds) Practical Identity and Narrative Agency, pp.121-145. London: Routledge.

Malpas, Jeff. 1999. "The Constitution of the Mind: Kant and Davidson on the unity of consciousness". International Journal of Philosophical Studies, 1-30.

Malpas, Jeff. 2000. "Acting at a Distance and Knowing from Afar: agency and knowledge on the internet". In The Robot in the Garden: telerobotics and telepistemology in the age of the internet, edited by Ken Goldberg, 108-124. Cambridge, MA: MIT Press.

Martin, C.B. 2008. The Mind in Nature. Oxford: Oxford University Press.

Martin, C.B. and Deutscher, Max. 1966. "Remembering".

Matthews, Steve. 2010. "Philosophy of Mind (Analytic)", in G. Oppy and N. Trakakis (eds), A

Companion to Philosophy in Australia and New Zealand, pp.413-419. Clayton, Vic: Monash University Press.

Maund, J.B. 1993. "Representation, Pictures, and Resemblance", in E.L. Wright (ed), New

Representationalisms: essays in the philosophy of perception, pp.45-69. Avebury Press.

Maund, J.B. 1995. Colours: their nature and representation. Cambridge: Cambridge University Press.

Maund, J.B. 2003. Perception. Chesham: Acumen.

Maund, J.B. 2006. "The Illusory Theory of Colours: an anti-realist theory". Dialectica 60:245-268.

Maze, John R. 1983. The Meaning of Behaviour. London: Allen and Unwin.

Maze, John R. 1991. "Representationism, Realism, and the Redundancy of 'Mentalese'". Theory and Psychology 1:163-185.

Melser, Derek. 2004. The Act of Thinking. Cambridge, MA: MIT Press.

Menary, Richard (ed). 2006. Radical Enactivism. Amsterdam: John Benjamins.

Menary, Richard. 2007. Cognitive Integration: mind and cognition unbounded. London: Palgrave.

Menary, Richard. 2010a. "Introduction to the special issue on 4E cognition". Phenomenology and the Cognitive Sciences 9:459-463.

Menary, Richard (ed). 2010b. The Extended Mind. Cambridge, MA: MIT Press.

Menzies, Peter. 1988. "Against Causal Reductionism". Mind 97:551-574. 
Menzies, Peter. 2003. "The Causal Efficacy of Mental States", in Physicalism and Mental Causation, edited by S. Walter and H. Heckmann, 195-223. Imprint Academic.

Menzies, Peter. 2007. "Mental Causation on the Program Model", in_The Common Mind: Essays in Honour of Philip Pettit, edited by G. Brennan, R. Goodin and M. Smith, pp.28-54. Oxford, Oxford University Press.

Menzies, Peter. 2009. "The Folk Theory of Colours and the Causes of Colour Experience", in lan Ravenscroft (ed), Mind, Ethics, and Conditionals: themes from the philosophy of Frank Jackson, pp. 141-160. Oxford: Clarendon Press.

Michell, Joel. 1988. "Maze's Direct Realism and the Character of Cognition". Australian Journal of Psychology 40:227-249.

Michell, Joel. 2000. "Normal Science, Pathological Science, and Psychometrics". Theory and Psychology 10:639-667.

Mitchell, Natasha. 2006. "The Mind-Body Problem Down Under". All in the Mind, ABC Radio National, 23 September. Transcript:

http://www.abc.net.au/rn/allinthemind/stories/2006/1745477.htm

Miller Seumas. 2002. "Against Collective Agency", in G Meggle (ed.) Social Facts and Collective Intentionality, pp.273-98. Frankfurt: Dr Hansel-Hohenhausen Ag.

Miller Seumas. 2005 "Artefacts and Collective Intentionality". Techne 9.

Mousley, Judith. 2001. Mathematical Understanding as Distributed Cognition. In Mind, Body and Society: emerging understandings of knowing and learning, edited by S. Gunn, 9-12. Melbourne:

Melbourne University Press.

Murphy, Dominic. 2006. Psychiatry in the Scientific Image. Cambridge, MA: MIT Press.

Murphy, Dominic. 2009. "Psychiatry and the Concept of Disease as Pathology", in M. Broome and L. Bortolotti (eds), Psychiatry as Cognitive Neuroscience: philosophical perspectives, pp.103-119.

Oxford: Oxford University Press.

Murphy, Dominic. 2010. "Philosophy of Psychiatry". Stanford Encyclopaedia of Philosophy. URL: http://plato.stanford.edu/entries/psychiatry/.

Nagasawa, Yujin. 2010. "Dualism" , in G. Oppy and N. Trakakis (eds), A Companion to Philosophy in Australia and New Zealand, pp.153-156. Clayton, Vic: Monash University Press.

Neander, Karen. 1995. "Misrepresenting and Malfunctioning". Philosophical Studies 79: 109-141.

Neander, Karen. 1996. "Swampman Meets Swampcow". Mind and Language 11:118-129.

Neander, Karen. 2006. "Content for Cognitive Science", in Graham Macdonald and David Papineau (eds), Teleosemantics: New Philosophical Essays,_167-194. Oxford: Oxford University Press.

Noble, William and lain Davidson. 1996. Human Evolution, Language, and Mind: a psychological and archaeological inquiry. Cambridge: Cambridge University Press.

Nowell, April and lain Davidson. 2010. Stone Tools and the Evolution of Human Cognition. University of Colorado Press.

O'Brien, Gerard. 1987. "Eliminative Materialism and our Psychological Self-Knowledge".

Philosophical Studies 52:49-70

O'Brien, Gerard. 1991. "Is Connectionism Common Sense?". Philosophical Psychology 4:165-78.

O'Brien, Gerard. 1998. "The Mind: embodied, embedded, but not extended". Symposium on Clark 1997. Metascience 7:78-83.

O'Brien, Gerard. 1999. "Connectionism, Analogicity, and Mental Content". Acta Analytica 22:111-31. O'Brien, Gerard and Rosalyn Diprose (eds). 1996. Exploring the Interface Between Philosophy of Mind and Philosophy of the Body: an annotated bibliography. Kensington, NSW: University of New South Wales Press.

O'Brien, Gerard and Jon Opie. 1997. "Cognitive Science and Phenomenal Consciousness: A Dilemma, and How to Avoid It". Philosophical Psychology 10:269-286.

O'Brien, Gerard and Jon Opie. 1998. "The Disunity of Consciousness". Australasian Journal of Philosophy 76:378-395. 
O'Brien, Gerard and Jon Opie. 1999a. "A Connectionist Theory of Phenomenal Experience". Behavioral and Brain Sciences 22:127-148.

O'Brien, Gerard and Jon Opie. 1999b. "A Defence of Cartesian Materialism". Philosophy and Phenomenological Research 59:939-963.

O'Brien, G. and J. Opie (2000). "Disunity Defended: A Reply to Bayne." Australasian Journal of Philosophy 78(2): 255- 263.

O'Brien, Gerard and Jon Opie. 2001. "Connectionist Vehicles, Structural Resemblance, and the Phenomenal Mind". Communication and Cognition 34:13-38.

O'Brien, Gerard and Jon Opie. 2004. "Notes Towards a Structuralist Theory of Mental

Representation", in H. Clapin, P. Staines and P. Slezak (eds),_Representation in Mind: New

Approaches to Mental Representation. Amsterdam: Elsevier.

O'Brien, Gerard and Jon Opie. 2006. "How Do Connectionist Networks Compute?". Cognitive

Processing 7: 30-41.

O'Brien, Gerard and Jon Opie. 2009. "The Role of Representation in Computation." Cognitive Processing 10:53-62.

O'Shaughnessy, Brian. (1980). The Will: a dual aspect theory. 2 vols. Cambridge: Cambridge

University Press.

O'Shaughnessy, Brian. (2002). "Dreaming". Inquiry 45:399-432.

Opie, Jon. 2010. "Consciousness" , in G. Oppy and N. Trakakis (eds), A Companion to Philosophy in

Australia and New Zealand, pp.123-127. Clayton, Vic: Monash University Press.

Oppy, Graham and David Dowe. 2011. "The Turing Test". Stanford Encyclopedia of Philosophy. URL:

http://plato.stanford.edu/entries/turing-test/.

Parsell, Mitch. 2005. "Context-sensitive inference, modularity, and the assumption of formal processing". Philosophical Psychology 18:45-58.

Parsell, Mitch. 2006. "The Cognitive Cost of Extending an Evolutionary Mind into the Environment". Cognitive Processing 7:3-10

Parsell, Mitch. 2009. "Quinean social skills: empirical evidence from eye-gaze against information encapsulation". Biology and Philosophy 24:1-19.

Parsell, Mitch. 2010. "Williams Syndrome: dissociation and mental structure". In W. Christensen, E. Schier, and J. Sutton (Eds.), ASCS09: Proceedings of the 9th Conference of the Australasian Society for Cognitive Science, 277-284. Sydney: Macquarie Centre for Cognitive Science.

Pettit, Philip. 1993. "A Definition of Physicalism". Analysis 53:213-223.

Pettit, Philip. 2003. "Groups with Minds of their Own", in Frederick Schmitt, ed., Socializing

Metaphysics, New York, Rowman and Littlefield, pp. 167-93.

Pettit, Philip. 2004. "Motion Blindness and the Knowledge Argument", in There's Something About

Mary: essays on phenomenal consciousness and Frank Jackson's Knowledge Argument, edited by P.

Ludlow, Y. Nagasawa and D. Stoljar. Cambridge, MA: MIT Press.

Pettit, Philip. 2007. "Neuroscience and Agent-Control", in Distributed Cognition and the Will:

individual volition and social context, edited by Don Ross, David Spurrett, Harold Kincaid, and G. Lynn

Stephens, 77-91. Cambridge, MA: MIT Press.

Pettit, Philip. 2009. Made with Words: Hobbes on language, mind, and politics. Princeton, NJ:

Princeton University Press.

Pettit, Philip and David Schweikard. 2006. "Joint Actions and Group Agents". Philosophy of Social Sciences 36:18-39.

Petocz, Agnes. 1999. Freud, Psychoanalysis and Symbolism. Cambridge: Cambridge University Press.

Price, Huw. 1989. "Action Explanation and the Nature of Mind". In Computers, Brains, and Minds:

essays in cognitive science, 221-251.

Priest, Graham and Damon Young (eds). 2010. Martial Arts and Philosophy: beating and nothingness. Open Court. 
Proudfoot, Diane and B. Jack Copeland. 2009. "Turing's Test: a philosophical and historical guide", in R. Epstein, G. Roberts, and G. Peters (eds), Parsing the Turing Test: Philosophical and Methodological Issues in the Quest for the Thinking Computer, pp.119-138. Berlin: Springer.

Radden, Jennifer. 2010. On Delusion. London: Routledge.

Ravenscroft, lan 1998. "Neuroscience and the Mind". Mind and Language 13:132-137.

Ravenscroft, Ian. 2005. Philosophy of Mind: a beginner's guide. Oxford: Oxford University Press.

Ravenscroft, lan. 2009. Is Folk Psychology a Theory? In RHPP, 131-147.

Redding, Paul. 1999. The Logic of Affect. Ithaca, NY: Cornell University Press.

Reynolds, Jack. 2006. "Deleuze and Dreyfus on l'habitude, coping and trauma in skill acquisition". International Journal of Philosophical Studies 14:563-583.

Reynolds, Jack. 2010. "Problem(s) of Other Minds: solutions and dissolutions in analytic and continental philosophy". Philosophy Compass 5: 326-35.

Rothfield, Philipa. 2008. "Philosophy and the Bodily Arts". Parallax 14:24-35.

Samuel, Geoffrey. 1990. Mind, Body and Culture: anthropology and the biological interface.

Cambridge: Cambridge University Press.

Schalley, A. and Drew Khlentzos (eds). 2007. Mental States, vol 2: language and cognitive structure. Amsterdam: John Benjamins.

Schellenberg, Susannah. 2008. "The Situation-Dependency of Perception". Journal of Philosophy 105:55-84.

Schellenberg, Susannah. 2010. "The Particularity and Phenomenology of Perceptual Experience". Philosophical Studies 149:19-48.

Schier, Elizabeth. 2007. "The Represented Object of Color Experience". Philosophical Psychology 20:1-27.

Schier, Elizabeth. 2008. "The Knowledge Argument and the Inadequacy of Scientific Knowledge". Journal of Consciousness Studies 15:39-62.

Schier, Elizabeth. 2009. "Identifying Phenomenal Consciousness".Consciousness and Cognition 18:216-222.

Schroeter, Laura. 2010. "Two-Dimensional Semantics". Stanford Encyclopedia of Philosophy (Winter 2010 Edition), Edward N. Zalta (ed.), URL: http://plato.stanford.edu/archives/win2010/entries/twodimensional-semantics.

Schwitzgebel, Eric. 2011. Perplexities of Consciousness. Cambridge, MA: MIT Press.

Sharpe, Matthew and Joanne Faulkner. 2008. Understanding Psychoanalysis. Acumen.

Slezak, Peter. 1986. Actions, Cognition and the Self. Synthese 66:405-435.

Slezak, Peter. 1990. "Reinterpreting Images". Analysis 50:235-243.

Slezak, Peter. 1995. "The 'Philosophical' Case against Visual Images", in P. Slezak, T. Caelli, and R. Clark (eds), Perspectives on Cognitive Science: theories, experiments, and foundations, pp.237-271. Norwood, NJ: Ablex.

Slezak, Peter. 2010. "Cognitive Science", in G. Oppy and N. Trakakis (eds), A Companion to Philosophy in Australia and New Zealand, pp.117-120. Clayton, Vic: Monash University Press.

Slezak, Peter and W.R. Albury (eds). 1988. Computers, Brains, and Minds: essays in cognitive science. Dordrecht: Kluwer.

Smith, Benjamin. 2007. "Body, Mind, and Spirit: towards an analysis of the practice of yoga". Body and Society 13:25-46.

Smith, Marquard (ed). 2005. Stelarc. Cambridge, MA: MIT Press.

Sparrow, Robert. 2009. "Building a Better WarBot : ethical issues in the design of unmanned systems for military applications". Science and Engineering Ethics 15:169-187.

Stelarc. 1991. Prosthetics, Robotics and Remote Existence: postevolutionary strategies. Leonardo 24:591-595.

Sterelny, Kim. 1983. "Mental Representation: what language is Brainese?". Philosophical Studies 43:365-382.

Sterelny, Kim. 1986. "The Imagery Debate". Philosophy of Science 53, 560-583. 
Sterelny, Kim. 1989a. “Fodor's Nativism”. Philosophical Studies 55:119-141.

Sterelny, Kim. 1989b. "Computational Functional Psychology: problems and prospects". In P. Slezak and W.R. Albury (eds), Computers, Brains, and Minds, pp.71-93. Dordrecht: Kluwer.

Sterelny, Kim. 1991. The Representational Theory of Mind: an introduction. Oxford: Blackwell. Sterelny, Kim. 1992. "Evolutionary Explanations of Human Behaviour". Australasian Journal of Philosophy 70:156-173.

Sterelny, Kim. 1993. "Refuting Eliminative Materialism on the Cheap?". Mind and Language 8:306315.

Sterelny, Kim. 1995. "Basic Minds". Philosophical Perspectives 9:251-270.

Sterelny, Kim. 2003. Thought in a Hostile World: the evolution of human cognition. Oxford: Blackwell. Sterelny, Kim. 2004. "Externalism, Epistemic Artefacts, and the Extended Mind", in R. Schantz (ed), The Externalist Challenge, pp. 239-254. Berlin: De Gruyter.

Sterelny, Kim. 2007. "Social Intelligence, Human Intelligence, and Niche Construction". Philosophical Transactions of the Royal Society B 362:719-730.

Sterelny, Kim. 2009. "Novelty, Plasticity and Niche Construction: the influence of phenotypic variation on evolution". In A. Barberousse, M. Morange, \& T. Pradeu (Eds.), Mapping the future of biology: evolving concepts and theories. Dordrecht: Springer.

Sterelny, Kim. 2010. "Minds: extended or scaffolded?" Phenomenology and the Cognitive Sciences 9:465-481.

Stich, Stephen and lan Ravenscroft, 1992, "What is Folk Psychology?" Cognition, 50: 447-68.

Stoljar, Daniel. 2000. "Physicalism and the Necessary a Posteriori". Journal of Philosophy 97:33-54.

Stoljar, Daniel. 2001. "Two Conceptions of the Physical". Philosophy and Phenomenological Research 62:253-281.

Stoljar, Daniel. 2006. Ignorance and Imagination: the epistemic origin of the problem of consciousness. Oxford: Oxford University Press.

Stoljar, Daniel. 2009. "Perception", in Central Questions of Philosophy, edited by John Shand, 51-67. Oxford: Blackwell.

Stoljar, Daniel. 2010a. "Identity Theory of Mind" , in G. Oppy and N. Trakakis (eds), A Companion to Philosophy in Australia and New Zealand, pp.219-223. Clayton, Vic: Monash University Press.

Stoljar, Daniel. 2010b. Physicalism. London: Routledge.

Stoljar, Daniel and Yujin Nagasawa. 2004. "Introduction", in There's Something About Mary: essays on phenomenal consciousness and Frank Jackson's Knowledge Argument, edited by P. Ludlow, Y. Nagasawa and D. Stoljar. Cambridge, MA: MIT Press.

Stoljar, Natalie. 1988. "Churchland's Eliminativism". Australasian Journal of Philosophy 66:489-497. Stone, Valerie E. and Philip Gerrans. 2006. "What's Domain-Specific about Theory of Mind?". Social Neuroscience 1:309-319.

Stone, Tony and Martin Davies. 1993. "Cognitive Neuropsychology and the Philosophy of Mind". British Journal for the Philosophy of Science 44:589-622.

Stotz, Karola. 2010. "Human Nature and Cognitive-Developmental Niche Construction".

Phenomenology and the Cognitive Sciences 9:483-501.

Suddendorf, Thomas and Corballis, Michael C. 2007. "The evolution of foresight: what is mental time travel and is it unique to humans?". Behavioral and Brain Sciences 30:299-313.

Sutton, John. 1998a. Philosophy and Memory Traces: Descartes to connectionism. Cambridge:

Cambridge University Press.

Sutton, John. 1998b. "Being There: putting philosopher, researcher, and student together again". Symposium on Clark 1997. Metascience 7:90-95.

Sutton, John. 2000a. "The Body and the Brain". In S. Gaukroger, J. Schuster, and J. Sutton (eds), Descartes' Natural Philosophy, pp.697-722. London: Routledge.

Sutton, John. 2000b. "Body, Mind, and Order: local memory and the control of mental representations in medieval and Renaissance sciences of self", in G. Freeland and A. Corones (eds), 1543 And All That: word and image in the proto-scientific revolution, pp.117-150. Dordrecht: Kluwer. 
Sutton, John. 2002. Porous Memory and the Cognitive Life of Things. In Tofts, Jonson, and Cavallero (eds) 2002, 130-141.

Sutton, John. 2006. "Distributed Cognition: domains and dimensions". Pragmatics and Cognition 14:235-247.

Sutton, John. 2007a. "Language, Memory, and Concepts of Memory: semantic diversity and scientific psychology", in M. Amberber (ed), The Language of Memory in a Cross-Linguistic Perspective, pp.4165. Amsterdam: Elsevier.

Sutton, John. 2007b. "Batting, Habit, and Memory: the embodied mind and the nature of skill". Sport in Society 10:763-786.

Sutton, John. 2008. "Between Individual and Collective Memory: interaction, coordination, distribution". Social Research 75:23-48.

Sutton, John. 2009a. "Dreaming", in P. Calvo and J. Symons (eds), Routledge Companion to the Philosophy of Psychology, pp.522-542. London: Routledge.

Sutton, John. 2009b. "Remembering", in P. Robbins and M. Aydede (eds), The Cambridge Handbook of Situated Cognition, pp.217-235. Cambridge: Cambridge University Press.

Sutton, John. 2010a. "Exograms and Interdisciplinarity: history, the extended mind, and the civilizing process". In R. Menary (ed), The Extended Mind, pp.189-225. Cambridge, MA: MIT Press.

Sutton, John. 2010b. "Observer Perspective and Acentred Memory: some puzzles about point of view in personal remembering". Philosophical Studies 148:27-37.

Sutton, John, Celia B. Harris, Paul G. Keil, and Amanda J. Barnier. 2010. "The Psychology of Memory, Extended Cognition, and Socially Distributed Remembering". Phenomenology and the Cognitive Sciences 9:521-560.

Sutton, John, Doris J.F. Mcllwain, Wayne D. Christensen, and Andrew Geeves. 2011. "Applying Intelligence to the Reflexes: embodied skills and habits between Dreyfus and Descartes". JBSP: Journal of the British Society for Phenomenology 42:78-103.

Sutton, John and Carl Windhorst. 2009. "Extended and Constructive Remembering: two notes on Martin and Deutscher". Crossroads 4:79-91.

Tanaka, Koji. 2004."Minds, Programs, and Chinese Philosophers: a Chinese perspective on the Chinese Room". Sophia 43:61-72.

Thiel, Udo. 2011. The Early Modern Subject: self-consciouxness and personal identity from Descartes to Hume. Oxford: Oxford University Press.

Tofts, Darren, Annemarie Jonson, and Alessio Cavallero (eds). 2002. Prefiguring Cyberculture: an intellectual history. Sydney and Cambridge, MA: Power Publications and MIT Press.

Tribble, Evelyn B. 2005. "Distributing Cognition in the Globe. Shakespeare Quarterly 56:135-55. Tribble, Evelyn B. 2011. Cognition in the Globe: attention and memory in Shakespeare's theatre. London: Palgrave Macmillan.

Tribble, Evelyn B. and Nicholas Keene. 2011. Cognitive ecologies and the history of remembering: religion, education, and memory in early modern England. London: Palgrave.

Tribble, Evelyn B. and John Sutton. 2011. "Cognitive Ecology as a Framework for Shakespearean Studies". Shakespeare Studies 39:94-103.

van Gelder, Tim. 1990. "Compositionality: a connectionist variation on a classical theme". Cognitive Science 14:355-384.

van Gelder, Tim. 1991. "What is the 'D' in 'PDP'? A survey of the concept of distribution. In W. Ramsey, S.P. Stich, and J. Tienson (eds), Connectionism and the Philosophy of Mind, pp.33-59. Dordrecht: Kluwer.

van Gelder, Tim. 1992. "Defining 'Distributed Representation'”. Connection Science 4:175-191. van Gelder, Tim. 1995. "What Might Cognition Be, If Not Computation?". Journal of Philosophy 92:345-381.

van Gelder, Tim. 1998a. "Monism, Dualism, Pluralism". Mind and Language 13: 76-97. van Gelder, Tim. 1998b. "The Dynamical Hypothesis in Cognitive Science". Behavioral and Brain Sciences 21:615-628. 
van Gelder, Tim. 1999. "Wooden Iron? Husserlian phenomenology meets cognitive science". In Naturalizing Phenomenology, edited by J. Petitot, F.J. Varela, B. Pacoud \& J-M. Roy, 245-

265.Stanford University Press.

van Gelder, Tim. 2005. "Enhancing and Augmenting Human Reasoning". In Cognition, Evolution, and Rationality: a cognitive science for the twenty-first century, edited by A.J.T. Zilhao, 162-181. London: Routledge.

van Gelder, Tim J., \& Lars F. Niklasson. 1994. "On Being Systematically Connectionist". Mind and Language 9:288-302.

van Gelder, Tim, and Robert F. Port. 1995. "It's About Time: an overview of the dynamical approach to cognition". In Mind as Motion: explorations in the dynamics of cognition, edited by R.F. Port and T. van Gelder, 1-44. Cambridge, MA: MIT Press.

Vincent, Nicole A. 2009. "Neuroimaging and Responsibility Assessments". Neuroethics 4:35-49.

Webb, Barbara. 1996. A Cricket Robot. Scientific American 275:94-99.

Webb, Barbara. 2001. Can robots make good models of biological behaviour? Behavioral and Brain Sciences 24:1033-1050.

Webb, Barbara. 2006. "Transformation, encoding and representation". Current Biology 6:R184-R185. Webb, Barbara. 2009. "Animals versus Animats: or why not model the real iguana?”. Adaptive Behaviour 17:269-286.

Wegner, Daniel M. 2002. The Illusion of Conscious Will. Cambridge, MA: MIT Press.

Wierzbicka, Anna. 1992. Semantics, Culture, and Cognition. Oxford: Oxford University Press. Wilson, Elizabeth A. 1998. Neural Geographies.

Wilson, Elizabeth A. 2010. Affect and Artificial Intelligence. University of Washington Press. Wilson, Robert A. 1994. "Wide Computationalism". Mind 103:351-372.

Wilson, Robert A. 2004. Boundaries of the Mind: the individual in the fragile sciences - cognition. Cambridge: Cambridge University Press.

Wilson, Robert A. 2005. "Collective Memory, Group Minds, and the Extended Mind Thesis". Cognitive Processing 6:227-236.

Wilson, Robert A. and Andy Clark. 2009. "How to Situate Cognition: letting nature take its course", in P. Robbins \& M. Aydede (eds), The Cambridge Handbook of Situated Cognition, pp. 55-77).

Cambridge: Cambridge University Press.

Wilson, Robert A. and Frank C. Keil. 1999. The MIT Encyclopedia of the Cognitive Sciences.

Cambridge, MA: MIT Press.

Windhorst, Carl. 2005. "The Slave Model of Autobiographical Memory". Cognitive Processing 6:253265.

Wrathall, Mark and Jeff Malpas (eds). 2000. Heidegger, Coping, and Cognitive Science. Cambridge, MA: MIT Press. 